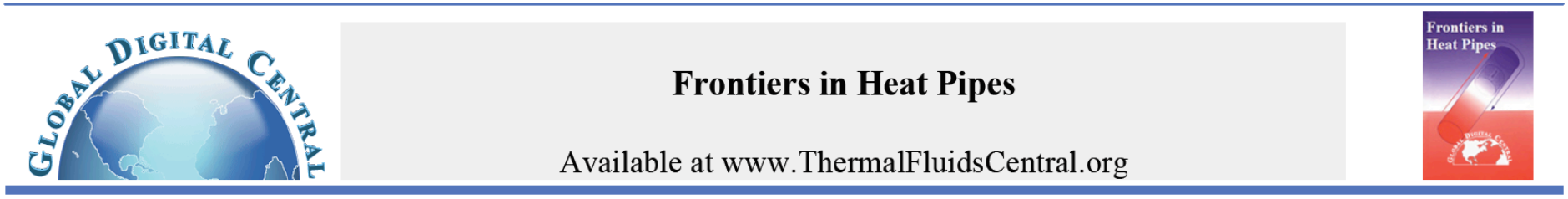

\title{
STATE-OF-THE-ART EXPERIMENTAL STUDIES ON LOOP HEAT PIPES
}

\author{
Stéphane Launay* and Martial Vallée \\ IUSTI, CNRS UMR 6595, Université de Provence, 5 rue Enrico Fermi, 13453 Marseille Cedex 13, France
}

\begin{abstract}
The present study provides a concise overview of the main feature evolution of Loop Heat Pipe (LHP) designs, in particular on the evaporator/compensation chamber, based on experimental studies published between 1998 and 2010. It presents a synthesis of results on LHP performances at steady-state, and observations related to the LHP dynamic behaviours, as start-up or oscillating behaviours. The objective of this review is to gather as much information from the LHP experimental studies so as to provide a database, and thus promote the development of tools for understanding and predicting the LHP behaviors. The review shows some omissions in the LHP description and in the results presentation that makes these data difficult to use for further studies. This review should promote some coordination for future experimental works on LHP.
\end{abstract}

Keywords: LHP, review, two-phase heat transfer system, porous, capillarity.

\section{INTRODUCTION}

A two-phase capillary pump loop, as Loop Heat Pipe (LHP), is an efficient heat transfer system based on the liquid-vapor phase change phenomena. A LHP consists of an evaporator, a condenser, a compensation chamber (also called reservoir), and some vapor and liquid transport lines (Fig. 1). Only the evaporator and eventually the compensation chamber contain wicks, while the other components could be made of smooth tubing. Like a conventional heat pipe, a two phase capillary loop uses capillary action to circulate the working fluid in a sealed enclosure and, in the process, to transfer waste heat from one location (heat source) to another (heat sink). Hence it contains no mechanical moving part to wear out or require electrical power to operate. Despite the apparent design simplicity and the theoretical operational robustness, a loop heat pipe is a complex system, whose operation involves multi-scale mechanisms, as thermo-hydraulic in porous media $(\sim 10 \mu \mathrm{m})$, wettability and evaporation in thin film $(\sim 1 \mu \mathrm{m})$, condensation two-phase flow $(\sim 1 \mathrm{~mm})$, and thermal and hydrodynamic couplings at the system scale $(\sim 1 \mathrm{~m})$. Detailed explanations on LHP operation are presented by Ku (1999) and Maydanik (2005).

Compared to conventional heat pipes, the originality of the LHP design assigns some additional advantages: (i) in term of operation against gravity with the use of wicks of very small pores (1 or 2 orders less than conventional heat pipes); (ii) in terms of capacity to transport large amounts of heat from the evaporator to the condenser, by decreasing the liquid and vapor fluidic resistance along the adiabatic zone (with the use of smooth tubing); (iii) in terms of heat transfer efficiency in the evaporator and the condenser, with the design of appropriated structure for evaporation and condensation phenomena; (iv) in terms of LHP integra- tion in the electronic architecture, with the flexibility in the evaporator and condenser positions also due to the use of smooth tubing in the adiabatic zone (tubing which are easily constrained).

Another two-phase capillary pump loop, named Capillary Pumped Loop (CPL), has similar advantages as LHP compared to heat pipe. The basic distinction between a traditional CPL and a traditional LHP lies in the fluidic and thermal attachment of the compensation chamber to the evaporator. But seemingly this distinction has a large impact on the design and operation of the capillary loops (Maidanik and Fershtater, 1997; Nikitkin and Cullimore, 1998). In what follows, only studies on LHP are reviewed as they cover most of the publications since the 2000s.

The appearance of LHP was a response to the challenge connected with the specific request of the aerospace technology for highly efficient heat transfer devices. Currently, LHP are already part of the thermal control of satellites (Russian Granat, Obzor spacecraft, Boeing's HS 702 communication satellites). As demonstrated for spacecraft thermal control systems, LHP can likely be a high performance heat transport device for terrestrial electronic cooling applications. The thermal management of modern electronics has become a problem of significant interest due to the demand for power and reduction in packaging size. The requirements of next-generation microprocessors in terms of power dissipation and heat flux rate will certainly outgrow the capability of today's thermal control technology. The most versatile feature of using LHP is the wide variety of design embodiments that can be realized to take advantage of the available space around the electronic to be cooled. Computer technology, in particular the PC notebook, is a new dimension of the LHP application, which was revealed by the appearance of miniature and fairly efficient devices (Pastukhov et al., 2003). Flexible, ramified, controllable,

\footnotetext{
*Associate professor at IUSTI - CNRS UMR 6595, Marseille, 13453, France

*Corresponding author.Email: stephane.launay@polytech.univ-mrs.fr
} 


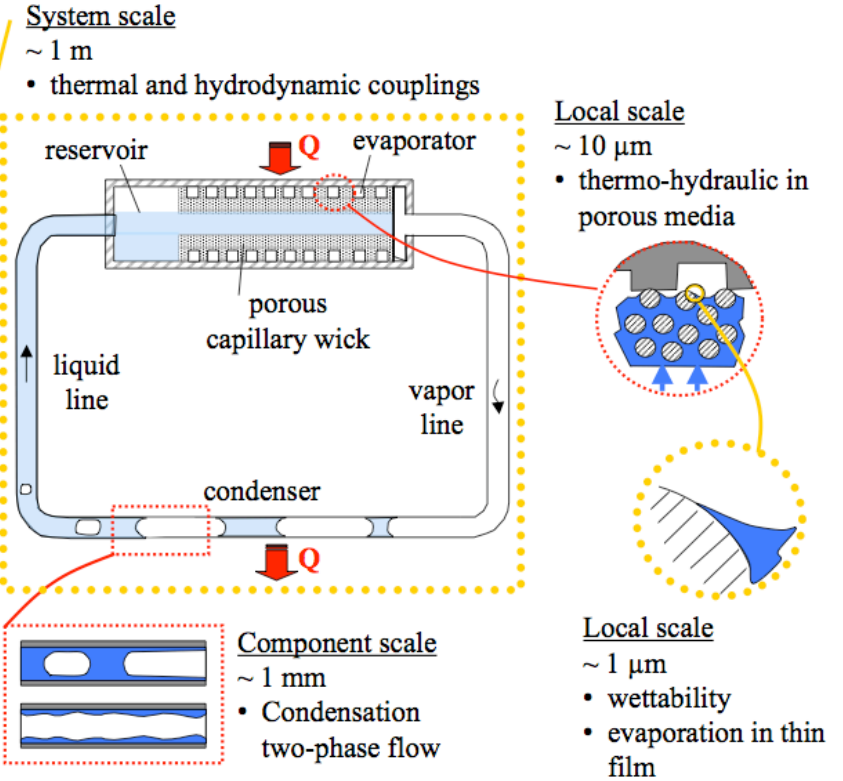

Fig. 1 Schematic of the main physical mechanismes in a LHP

reversible, miniature or cryogenic are some of the LHP designs that have been presented in the literature (Maydanik, 2005).

The first experimental studies on LHP (years 80-90) mainly focused on the characterization of the performance and the behaviors of the LHP when these ones are subjected to a protocol in connection with applications and conditions of space. For reasons of economic issues, the LHP are generally only briefly described. These studies, while important in the loop development process, do not allow people outside the project to make the most of these data for further reflection on the operation and optimization of such systems. While the space applications are a driving force for the development of LHP, extending their use in the thermal control of electronic components for terrestrial applications has generated additional interest on this topic to a wider community of researchers. Thus, from the 2000s, there has been an intensification of the literature on this subject. In light of these articles, this new community seems inclined to share more detailed information on the design and sizing of the LHP.

The objective of this review is to gather as much information from these experimental studies so as to provide a database, and thus promote the development of tools for understanding and predicting the LHP behaviors. Indeed, we find in the literature some transient models capable of reproducing fairly well the dynamic behavior of LHP (Launay et al., 2007a; Vlassov and Riehl, 2008) but after adjustment of certain variables, either due to lack of information issued by the experimental study, or by the difficulty of characterizing some of these variables. This work also has a role to coordinate future experimental studies stressing the need to better describe a number of elements of the LHP in order to promote futher the exploitation of such data.

\section{SYNTHESIS OF LHP EXPERIMENTAL STUDIES}

Tables 1 and in "Appendix A" summarize an exhaustive review of LHP experimental studies published between 1998 and 2010. Listed in the table are the papers for which the LHP characteristics and the results are substantial enough to generate a qualitative or quantitative analysis. This database, which includes more than fifty LHP of various characteristics, is a source of information to start a constructive reflection to the improvement of the LHP knowledge. Only the studies of LHP with relatively conventional design (with one evaporator and one condenser) are presented in these tables. In this review has been deliberately excluded the LHP of cryogenic application because of their specificity (secondary capillary pump, high pressure tank). The LHP with multiple evaporators and/or multi-condensers are poorly represented in this table because of the difficulty of access to the geometry data and to the results formulation. The reader may refer to the articles of Hoang et al. (2003) and Mo and Liang (2006) for the cryogenic LHP, and to the article of Ku et al. (2009) for multiple LHP evaporators/condensers for more information on the specificities of these kinds of two-phase capillary loops.

In the Tables 1 and "Appendix A", the LHP studies are arranged chronologically. Table 1 provides a concise overview of the main feature evolution of the LHP designs, in particular on the Evaporator/Compensation Chamber (E/CC), as well as the objectives of the various studies. Although the E/CC of cylindrical design were initially preferred by the researchers (for various reasons of manufacturing processes and/or of the mechanical strength in connection with the use of ammonia as the working fluid), a number of new E/CC configurations have been proposed during the years 2009-2010. The diversity of these designs is a response to the use of LHP for the thermal control in the Earth's field (use of other working fluids, high flux densities, implementation challenge, etc.). The main design characteristics of the E/CC are developed in subsection 3.2.

It emerges from Table 1 that the objectives of most of the experimental investigations conducted on the various LHP are to study their thermal performance, or to study their behavior during start-up or a power cycling test. Some of these studies concentrate on analyze the influence of certain parameters, such as the fluid filling ratio, the working fluid nature, the relative position of the evaporator to the reservoir and the condenser, or the capillary wick characteristics on the LHP behavior. Readers, who are interested in analyzing the effect of parameters on the LHP operation, may refer to the review paper of Launay et al. (2007b). The present paper focuses more specifically on the summary of the results and observations related to steady-state and dynamic behaviors of the LHP, the start-up, and the oscillating behaviors. This analysis is presented in Section 4.

A more detailed summary of the LHP experimental studies is presented in Table "Appendix A". For each LHP, two parts can be distinguished. The first part presents the LHP specificity and the description (dimensions, materials) of each of these components. The second part summarizes the main objectives of the experimental study, the installed instrumentation and the thermal performance obtained for the LHP. We can note a lack of information in this table, particularly regarding the characteristics of the capillary wick, the hydraulic connections between the evaporator and reservoir, and the thermal resistance of the evaporator RE. In this table, it would be interesting to add the effective thermal conductivity of the porous wick, but this data is too infrequently reported in the literature.

It is observed that the development trend is the miniaturization of the LHP with proposals of various designs of E/CC. These proposals are a response to various kinds of criteria:

- New applications involving the selection of other working fluids (and then some other materials);

- Implementation in electronic module architecture: constraints in terms of volume and containment;

- Operation reliability: durability, thermal and environmental constraints;

- Economic: weight, cost of manufacturing and packaging;

- Thermal performance: efficiency of the heat transfer and the heat transport;

- Knowledge: choice of materials, and specific instrumentation.

How to define the transition between a conventional LHP and a miniature LHP? Various criteria have been found in the literature to answer this question. For Maydanik (2004), a LHP is considered as minia- 
Table 1 Synthesis of LHP experimental studies.

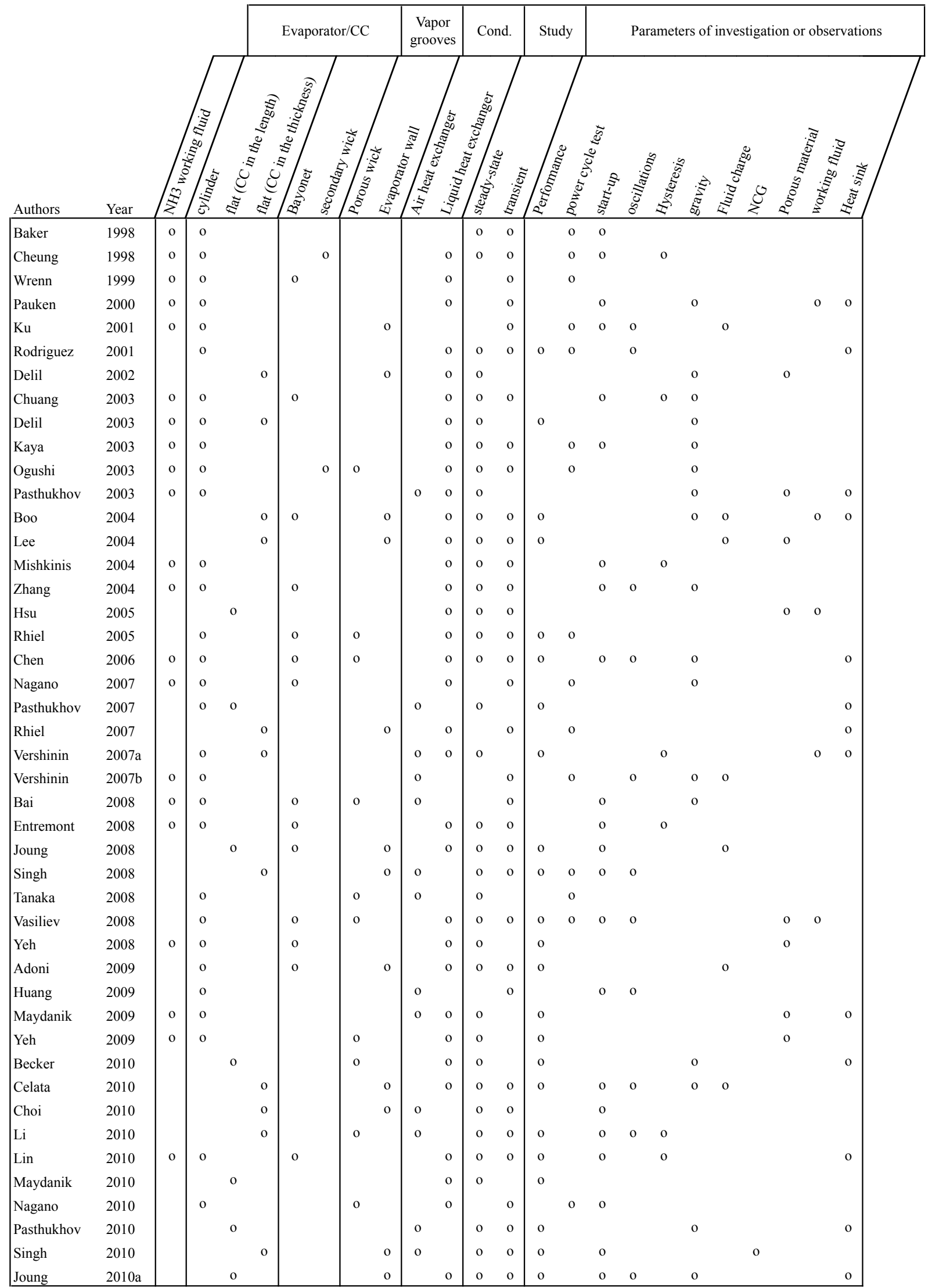


ture if the evaporator outer diameter does not exceed $8 \mathrm{~mm}$ (with or without the saddle?), and if the diameters of the liquid and vapor lines are less than $3 \mathrm{~mm}$. Moreover, for flat evaporators, the ratio between the length and the thickness should not be less than 2. For Li et al. (2010a), the miniature LHP is defined only from the dimensions of the liquid and vapor line diameters (the diameter must be in between $1-3 \mathrm{~mm}$ ).

\section{DESCRIPTION OF LOOP HEAT PIPES}

Maydanik (2005) proposed a LHP classification depending on the LHP configuration, the design of its components, the temperature level and the control strategy (Table 2). This classification is intended to show a general panel on the various types of existing LHP.

Table 2 Classification of LHPs (Maydanik, 2005)

\begin{tabular}{|c|c|c|c|}
\hline LHP design & LHP dimensions & Evaporator shape & Evaporator design \\
\hline $\begin{array}{l}\text { - Conventional (diode) } \\
\text { - Reversible } \\
\text { - Flexible } \\
\text { - Ramified }\end{array}$ & $\begin{array}{l}\text { - Miniature } \\
\text { - All the rest }\end{array}$ & $\begin{array}{l}\text { - Cylindrical } \\
\text { - Flat disk-shaped } \\
\text { - Flat rectangular }\end{array}$ & $\begin{array}{l}\text { - One butt-end compensation chamber } \\
\text { Two butt-end compensation chambers } \\
\text { - Coaxial }\end{array}$ \\
\hline Condenser design & $\begin{array}{l}\text { Number of evaporators } \\
\text { and condensers }\end{array}$ & Temperature range & Operating-temperature control \\
\hline $\begin{array}{l}\text { - Pipe-in-pipe } \\
\text { - Flat coil } \\
\text { - Collector }\end{array}$ & $\begin{array}{l}\text { - One } \\
\text { - Two and more }\end{array}$ & $\begin{array}{l}\text { - Cryogenic } \\
\text { - Low-temperature } \\
\text { - High-temperature }\end{array}$ & $\begin{array}{l}\text { - Without active control } \\
\text { - With active control }\end{array}$ \\
\hline
\end{tabular}

In this section, we propose to describe in more detail each LHP components, and then, to make the connection between these components and the behaviors or the thermal performances of the LHP. The subsections are presented in a certain order that might look like a LHP design procedure for a given application. Obviously, the design procedure can not be linear and requires flow back and forth between the various components in the same way that there are many thermo-hydraulic couplings between the LHP components.

\subsection{Working fluids}

As part of a LHP design procedure for a targeted application, the selection of the working fluids is the first step and must satisfy a number of criteria:

- To be in liquid-vapor state at the minimum operating temperature, outside the storage phase.

- The saturation pressure of the fluid at the maximum operating temperature, $P_{\text {sat }}\left(T_{\max }\right)$, should be below the critical pressure $P_{c}:$ In general, the maximum allowable pressure is less than $P_{c}$ and is limited by the mechanical strength of the LHP elements. A decrease in the maximum pressure induces a reduction in the wall thickness of the materials that make up the system, and consequently, a reduction of the size and mass of the LHP.

- Respond to standards in terms of environmental, hazardous and harmful properties.

In a second step, other criteria, most likely to characterize the ability of the fluid to transfer heat for this type of system, have been proposed by Launay et al. (2010). These criteria, developed under the name of numbers of Merit, are linked with the critical mode of the LHP operation.

From this new selection, it is then necessary to address each of these fluids and the compatible materials to avoid chemical reactions. These chemical reactions would cause a degradation of the mechanical strength or the tightness of the LHP, or a generation of condensable gases which could alter the LHP operation. The materials covered are those that make up the structure of LHP (shell of the evaporator tank, liquid line and vapor condenser) and the capillary structure. This problematic has been extensively treated in the heat pipe development. Information on the heat pipe life test procedures may be found in Reay and Kew (2006). Mishkinis et al. (2010) have performed a survey of possible solutions and selection of potentiel working fluids and LHP materials for envelope and wick.

According to the various criteria listed above, ammonia seems to be the most appropriate fluid for the thermal control in space applications. From Tables of Appendix A, it is the fluid that was the most used. In such applications, other alternative fluids such as propylene and acetone have rarely been tested. For ammonia, Stainless Steel is the most common material that has been used for the container, while the Nickel or Titanium materials have been used for the capillary structure.

The extension of the LHP application to ground and to some operating temperature ranges around 20 to $100{ }^{\circ} \mathrm{C}$ has guided researchers to other working fluids. Fluids such as methanol, acetone, ethanol and more unusually, pentane and R134a, were used for this type of application, water, according to its thermo-physical characteristics and its innocuous nature, is a working fluid that is increasingly used. The use of water as the working fluid partly explains the recent use of copper as the container material and the capillary structure of the LHP.

\subsection{Evaporator/Compensation Chamber (E/CC)}

While initially the E/CC of cylindrical shape was preferred, partly for reasons of mechanical strength due to the use of ammonia and to the spatial context, recent studies have shown a diversity of E/CC designs. The main categories of E/CC designs presented in the literature are shown in Fig. 2. The E/CC designs can be classified in three categories :

- The E/CC of cylindrical shape with the CC located in the extension of the evaporator (Fig. 2(a))

- The E/CC of flat shape with the reservoir located in the extension of the evaporator (Fig. 2(b))

- The E/CC of flat shape with the reservoir located in the thickness of the evaporator (Fig. 2(c)). For this case, the evaporators can be a square, rectangular or disc-shaped.

The proposal for these various geometries of E/CC is a response to expanding applications of the LHP with the issue of miniaturization for a better implementation (area, volume) within a 3D architecture of the electronic modules, and with the issue of higher dissipated heat flux rates.

What is the LHP problematic related to the miniaturization and to the increase of the heat flux rates? The operation and performance of a LHP are very sensitive to the thermal hydraulic link between the evaporator and the reservoir. The E/CC miniaturization tends to reduce the conductive thermal resistance between the evaporator and the compensation chamber, and thus to increase the part of parasitic heat flux on the heat transferred to the condenser by latent heat. It may be reminded here that the parasitic heat flux is compensated by the subcooling heat flux of the liquid flow at the reservoir inlet: increase in the parasitic heat flux tends to increase the liquid subcooling, and hence to increase the LHP operating temperature.

In the literature, various approaches are implemented to reduce the amount of parasitic heat flux:

- Using materials of medium thermal conductivity (Stainless Steel, Inconel) for the E/CC container;

- Reducing the wall thickness, up to $0.25 \mathrm{~mm}$ for a cylindrical E/CC in Stainless Steel (Pastukhov et al., 2003). The wall thickness depends on the shape and the material of the evaporator, in particular to prevent a deformation of the container under the pressure force of the working fluid. The procedures of manufacturing or machining of the component can also define the allowed minimum thickness.

- Using a capillary structure of low or medium thermal conductivity (polyethylene, polypropylene, PTFE, Stainless Steel, Titanium); 
- Reduction of the conductive section between the evaporator and the reservoir by selecting the appropriate design of the E/CC (Riehl and Siqueira, 2006)

- Using materials of various kinds for the evaporator compared to the reservoir (Adoni et al., 2009)

In contrast to these trends, some copper miniature E/CC, which show high performance thermal characteristics, have been presented in the literature (Li et al., 2010a). According to the analytical model of Launay et al. (2008), it could be noted that increasing the thermal resistance of the conductive wall $\left(R_{\text {wall }}\right)$ or the porous wick $\left(R_{w}\right)$ is not a sufficient condition to reduce the parasitic heat flux. For a miniature LHP, the role of the ratio $R_{E} / R_{\text {wall }}$ is predominant and must be reduced. $R_{E}$ characterizes the thermal resistance between the heat source and the vaporization front in the capillary wick, mainly including the conductive thermal resistances of the container wall at the evaporator and of the dry region in the capillary wick. If $R_{\text {wall }}$ can be easily characterized globally, $R_{E}$ is much more complex. Indeed, the thermal resistance $R_{E}$ includes a set of coupled physical mechanisms, some of which are difficult to characterize, such as:

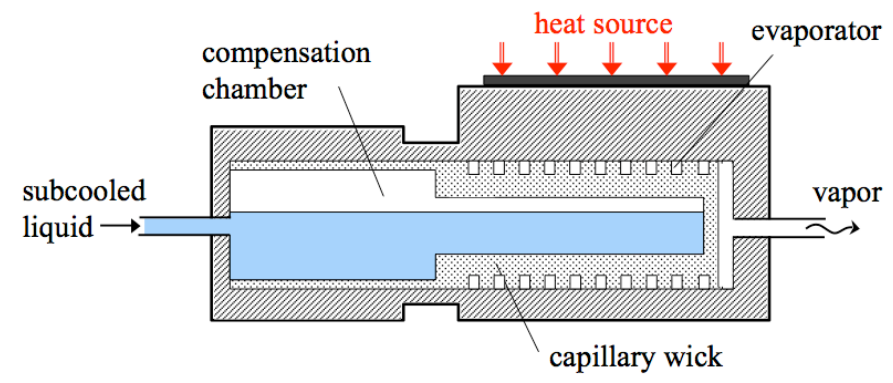

(a) E/CC of cylindrical shape

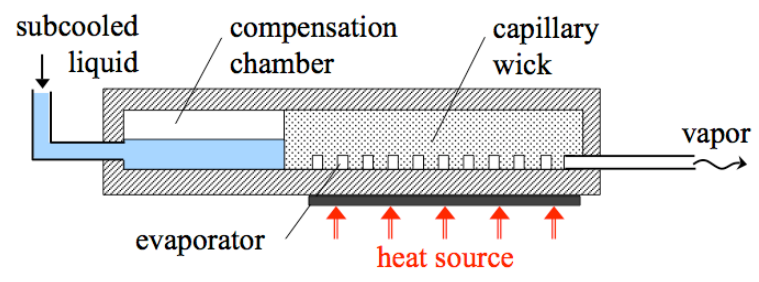

(b) E/CC of flat shape with the reservoir located in the extension of the evaporator

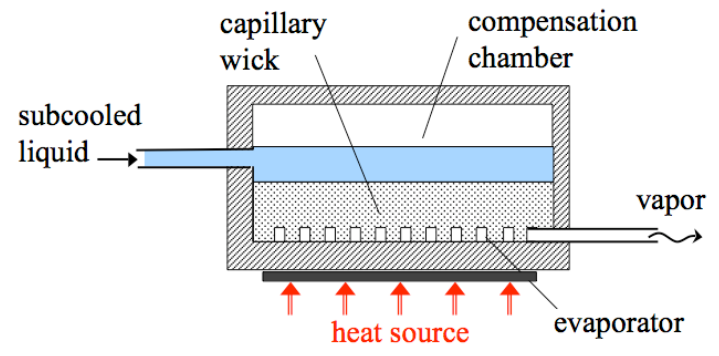

(c) E/CC of flat shape with the reservoir located in the thickness of the evaporator

Fig. 2 Schematics of evaporator designs
- The heat conduction in the thickness of the evaporator container;

- The thermo-mechanical contact between the evaporator container and the capillary wick. The quality of the contact depends on a number of parameters, such as the surface roughness (related to the manufacturing process and/or machining) of the elements in contact, the method of assembly/installation of the evaporator (mechanical clamping, brazing, soldering?). This contact quality can also be dependent on a consideration of cost. In the literature, there is little or no information regarding the implementation or the control of the wick/wall mechanical contact;

- The thermo-hydraulic phenomena in the capillary wick, including the conduction, the liquid and vapor flows, the vaporization, and the capillarity associating the phenomenon of the fluid/porous wettability. All these mechanisms contribute to the position of the evaporation front in the capillary wick. The thermo-hydraulic characteristics of the porous wick play a fundamental role.

Various experimental approaches have been implemented to improve the performance of the E/CC, especially by playing on:

- The characteristics of the capillary wick

- The characteristics of the vapor channel

- The hydraulic link between the evaporator and reservoir

- The use of a conductive heat spreader (saddle) between the heat source and the evaporator container.

Porous characteristics Figure 3 shows the values of the porosity $\epsilon$ and the permeability $K$ as a function of the pore diameter for the capillary wicks, whose characteristics are specified by the authors of the various experimental studies on LHP (Tables of Appendix A). In Fig. 3, there is no distinction between the nature of the porous materials. There is a wide dispersion of $\epsilon$ and $K$ for a given pore diameter. The porosity is between 30 and $75 \%$ regardless of the pore diameter $20 \mu \mathrm{m}$. The permeability is between $10^{-14}$ and $3.10^{-13} \mathrm{~m}^{2}$ and tends to increase with the pore diameter. However, one must be cautious about analyzing this chart.

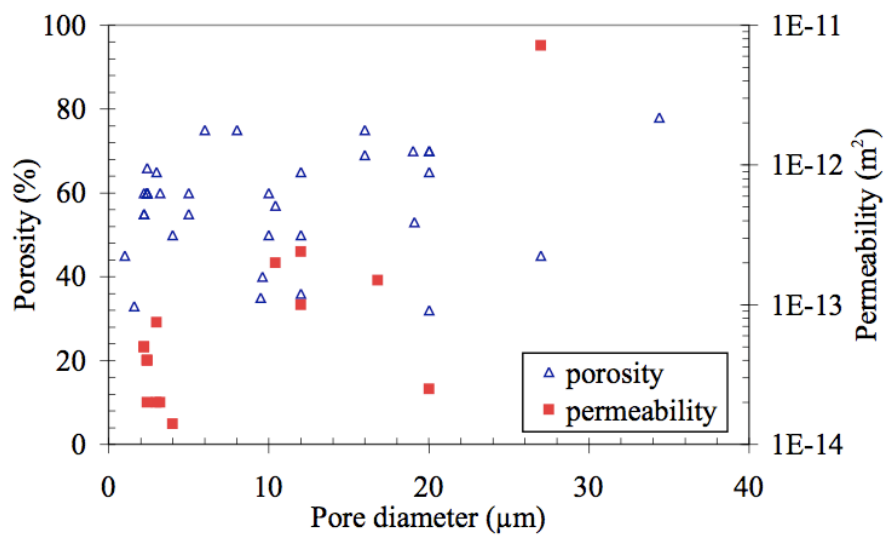

Fig. 3 Properties of common LHP wicks (Hoang and Ku, 2003)

Is the dispersion of these characteristics due to the material, the manufacturing process, or the definition or characterization of the wick pore diameter? If the porosity and permeability are generally well defined for a given porous material, the concept of pore diameter seems more difficult. For the ideal case of porous spherical particles with uniform diameter, the equation of Kozeny-Carman connects the particle diameter to the permeability and porosity $\left(K \sim \epsilon^{3} * \oslash_{p}^{2}\right.$ ). What is it for polydisperse porous wicks that are more representative of the LHP capillary structures? What 
size of pores must be considered in calculating the capillary limit in relation to the pore distribution? This information is rarely made explicit in the literature of LHP, some authors (Becker et al., 2010) clarify the nature of the pore diameter by the expression of "breakdown pore radius".

Hoang and $\mathrm{Ku}$ (2003) have compiled some porous characteristics by distinguishing the materials. This compilation shows some dependence (increase) of the permeability with the pore diameter (Fig. 4). Concerning the nature of the porous materials used as LHP capillary structure, Nickel sintered porous is the most commonly encountered, followed by the use of polymers (polyethylene, polypropylene, PTFE), Titanium, Copper, Stainless Steel, and more marginally Iron Oxide, Brass, and Nickel-Chromium. The use of copper as a base material of the LHP capillary wick came out recently. The pore diameters of these various porous materials are between 1 and $20 \mu \mathrm{m}$, except for copper, which has larger pore diameters (between 20 and $100 \mu \mathrm{m}$ ). Results obtained by $\mathrm{Li}$ et al. (2010a) indicate that the use of wicks of large pore diameter is not necessarily a handicap.

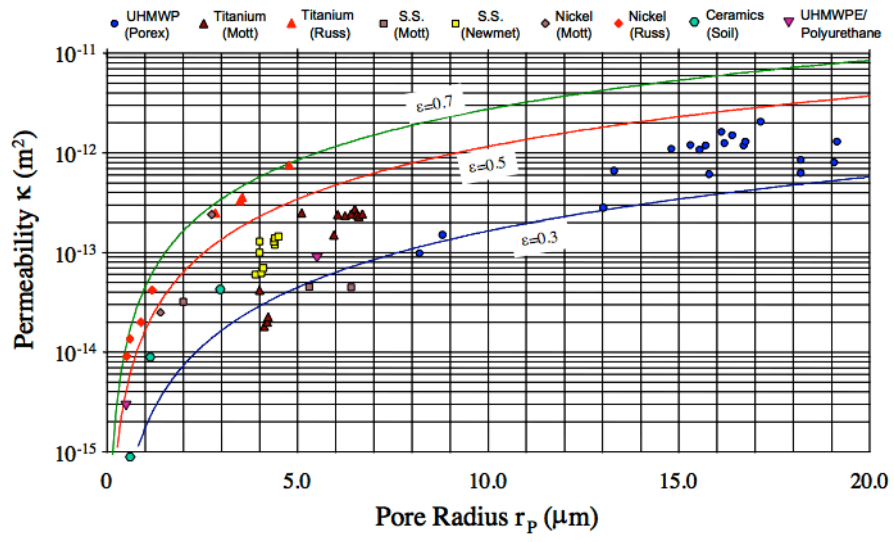

Fig. 4 Properties of common LHP wicks (Hoang and $\mathrm{Ku}, 2003$ )

The selection of porous properties is critical for the performance of the LHP. According to Hoang and $\mathrm{Ku}$ (2003), the required properties for the capillary wick are: (i) small pore diameters to ensure a large capillary driving pressure, (ii) a large porosity and permeability for lower hydraulic resistance, (iii) a low thermal conductivity to minimize parasitic heat flux through the porous wick. An increase of the permeability with the pore diameter is observed experimentally and is predicted by theoretical models as well. Consequently, conditions (i) and (ii) may not be achieved simultaneously: the hydraulic performance of a capillary wick can be regarded as a balance between capillary forces and flow properties.

Li et al. (2010b) studied the effect of various parameters relating to the manufacturing process on the properties of a sintered-nickel porous. The studied parameters are the mechanical stress applied to the sample during manufacturing, the size and the concentration of microcrystalline cellulose added to the sintered-nickel porous. For an equivalent porosity between the various samples, the measured hydraulic performance (time evolution of the saturation level of water in the capillary structure) seems to be to the benefit of the porous wick of smaller diameter pores compared to those of higher permeability. Yeh et al. (2008) have developed a biporous wick structure of sintered nickel ( $3 \mu \mathrm{m}$ in diameter) from inclusion of $\mathrm{Na}_{2} \mathrm{CO}_{3}$ space-holder (32-48 $\mu \mathrm{m}$ in diameter) (Fig. 5). The distribution of the pore diameters for the mono-porous (without inclusion) and biporous (with inclusion) are shown in Fig. 6. The average pore diameters and permeabilities are $10 \mu \mathrm{m}$ and $10^{-12} \mathrm{~m}^{2}$, respectively, for the mono-porous, and 7 and $24 \mu \mathrm{m}$ ( 2 average pore diameters) and $10^{-11} \mathrm{~m}^{2}$ for the bi-porous. This example of manufacturing process shows the feasibility of raising the contradiction between the opposite effects of the pore diameter and the permeability on the hydraulic performance of the capillary structure.

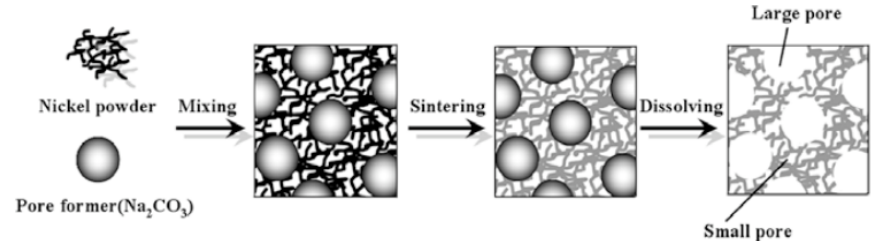

Fig. 5 Schematic view of the process to produce bi-porous wicks (Yeh et al., 2009)

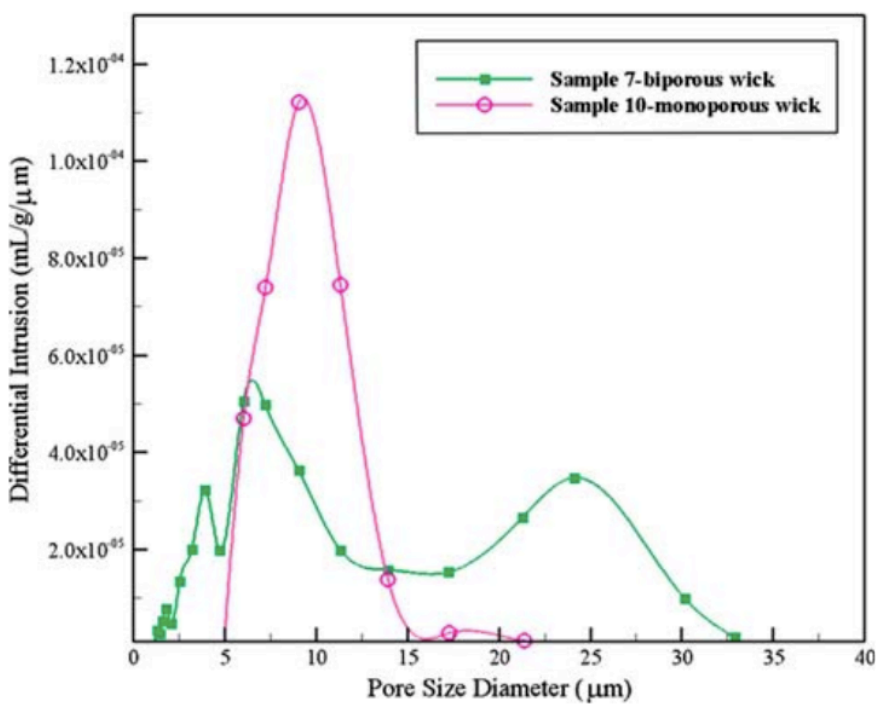

Fig. 6 Measured pore size distribution of monoporous and bi-porous wicks (Yeh et al., 2008)

What about the thermal properties of porous media, such as the thermal conductivity? The characterization of the porous thermal conductivity is as complex as the characterization of the pore diameter as it is highly dependent on the manufacturing process. This may explain why this characteristic is rarely provided by the researchers in LHP studies? In the literature, one can find different formulations of the equivalent thermal conductivity of porous $k_{e f f}$ according to the intrinsic thermal conductivity of each element (metal and fluid) and to the porosity (Mo et al., 2006). A large dispersion of results for $k_{\text {eff }}$ has been obtained depending on the formulations. It appears that the choice of one or the other formulations can be made retrospectively, by comparison with measurements. For a dry porous nickel wick, Li et al. (2010b) measure an effective thermal conductivity $\left(k_{e f f}\right)$ of $3 \mathrm{~W} / \mathrm{m} \cdot \mathrm{K}$ for a wick porosity of $75 \%$, and Mo et al. (2006) measure a $k_{\text {eff }}$ of $6 \mathrm{~W} / \mathrm{m} \cdot \mathrm{K}$ for a wick porosity of $56 \%$. According to these measurements, the thermal conductivity of the nickel material, which is deduced from a parallel scheme formulation, is therefore up to $13 \mathrm{~W} / \mathrm{m} \cdot \mathrm{K}$. This value, far from the theoretical conductivity of nickel $(90 \mathrm{~W} / \mathrm{m} \cdot \mathrm{K})$, can be explained by the discontinuity of the material at each point of contact of the nickel sintered beads. Moreover, Mo et al. (2006) observed a significant increase in the effective thermal conductivity of a porous media saturated with liquid (transition from 6 to $8 \mathrm{~W} / \mathrm{m} \cdot \mathrm{K}$ without and with water, respectively) compared to the expected result with the formulations. This significant increase can be partly explained by a change in the quality of the contact between balls (replacement of air by liquid), thereby decreasing the thermal contact resistance.

This effect was also observed by Xin et al. (2010) for a monodisperse porous media in Nickel and a bidisperse porous media in Nickel and Copper (Nickel-Copper powder mixtures, $D_{N i}=2.5 \mu \mathrm{m}$ and $D_{C u}$ $=13 \mu \mathrm{m})$. This study also reveals, that the effective thermal conductivity $k_{e f f}$ of the bidisperse porous media in $\mathrm{Ni} / \mathrm{Cu}$ is much lower than the one 
of pure monodisperse porous in $\mathrm{Ni}$, and that Keff decreases when the concentration of copper increases. The authors justify the decrease of $k_{e f f}$ of the powder mixture by the formation of $\mathrm{Ni}-\mathrm{Cu}$ solid solution.

Vapor channels The position and the shape of the vapor channels are other parameters that can influence the thermal resistance at the evaporator RE. Thus, among the LHP experimental studies, vapor channels have been machined either at the inner surface of the evaporator container, or at the outer surface of the porous wick. The hydraulic diameter and the channel spacing are variables (of the order of the millimeter) and some transverse channels (collectors) are sometimes added to the longitudinal ones (Figures of Appendix B). The choices of the position and the dimensions of the vapor grooves can respond to a criterion of heat transfer performance, or to a criterion related to the feasibility and to the cost of the groove machining.

The theoretical study of Altman et al. (2002) shows the effect of the design of the vapor channels on the heat transfer from the wall to the evaporation front position in the porous wick (Fig. 7). The characterization of the evaporation front shape in the porous wick and of the thermal performance that are derived for various sets of parameters is the goal of many modeling studies (Figus et al., 1999; Kaya and Goldak, 2006).

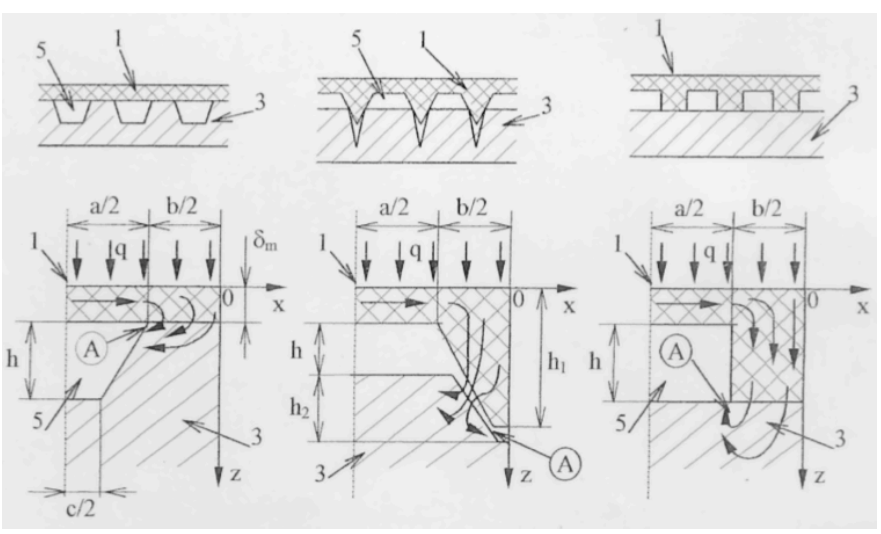

Fig. 7 Design and technology versions and schemes of heat transfer of LHP evaporators (Altman et al., 2002)

Thermal-hydraulic link between the evaporator and the compensation chamber To make the LHP more flexible, the E/CC should operate whatever its orientation (evaporator above or below the reservoir). The hydraulic link between the reservoir and the evaporator is then necessary to ensure the continuity of the liquid flow, and this, even in an unfavorable position (evaporator above the reservoir). The hydraulic link should promote a homogeneous hydration of the main capillary wick to avoid a local and premature drying of the evaporator.

Although the nature of the hydraulic link is rarely described in the literature, mainly three techniques have been implemented:

1. use of a capillary wick, called secondary wick. Its role may be double: (i) maintain the hydraulic connection between the fluid pool in the reservoir and the base of the main capillary wick, (ii) act as a thermal barrier between the evaporator and reservoir. Its required characteristics are a high permeability and a low thermal conductivity.

2. use of a bayonet that can transport the liquid from the liquid line directly to the evaporator core. This technique is generally used for cylindrical evaporators and maybe coupled with a secondary wick.

3. use of gravity effect by placing the reservoir above the evaporator. This is the general case of the flat evaporators operating at horizontal and with the reservoir above the evaporator.
Lin et al. (2010) have proposed an original configuration of E/CC, which includes a bayonet and two reservoirs located at the ends of the cylindrical evaporator. This configuration allows the LHP, without any secondary wick, to operate whatever its position.

Metal saddle at the evaporator A better distribution of heat flux from the heat source to the evaporator tends to homogenize the temperature of the heat source, while reducing the temperature for a given heat flux. Thus, the flat evaporators seem more convenient to evenly distribute the heat flux. In the case of cylindrical evaporators and flat heat sources, a metal saddle (usually in aluminum or copper) is inserted between the two components. The quality of the heat diffusion to the evaporation front position in the porous wick is then dependent on the geometry of the metal saddle and on its fixation with the cylindrical evaporator. The supplement of the metal saddle is not without any consequences on the integration of the evaporator in a 3D architecture of electronic modules, and on the LHP typical operation. In terms of integration, the saddle generates additional weight and thickness to the LHP evaporator. In terms of LHP operation, the thermal inertia of the saddle can significantly change the LHP dynamic behavior, especially on the fast transient behaviors as brutal startups at high heat fluxes. This point may be critical if the thermal diffusion in the saddle becomes the limiting heat transfer regarding the LHP startup. According to $\mathrm{Ku}$ and Rodriguez (2003), the thermal inertia of the saddle may also be one of the parameters responsible of the oscillating behaviors during steady-state operation, particularly on the low-frequency temperature oscillations.

A compromise should be found between the thermal inertia and the temperature homogenization at the heat source. In the LHP literature, the metal saddle is rarely described. However, this description is needed, particularly for the validation of transient LHP modeling.

\subsection{Condenser}

The role of the condenser is to evacuate the heat flux, which is dissipated by the heat source, to the surroundings.

The overall heat exchange coefficient at the condenser includes condensation, heat diffusion by conduction through the walls of the heat sink, and convective or radiative heat transfers with the surrounding environment that can be the air, the water or the space environment. In the literature, the diversity of the condensers can be represented by different combinations of the three element classes of Table 3. The most common condensers are the condensation in tube and a heat flux evacuation, either through a liquid cooled plate, or by a counter-current liquid flow heat exchanger (tube-in-tube), or by convective heat transfer of the ambient air over a finned surface heat exchanger.

Table 3 Classification of condenser elements.

\begin{tabular}{|l|l|l|}
\hline $\begin{array}{l}\text { Condensation } \\
\text { cross-section }\end{array}$ & Thermal link & $\begin{array}{l}\text { Modes of external heat } \\
\text { transfer }\end{array}$ \\
\hline - circular & - plate heat exchanger & - air forced convection \\
- annular & $\begin{array}{l}\text { - finned heat exchanger } \\
\text { - tube-in-tube heat ex- } \\
\text { changer }\end{array}$ & $\begin{array}{l}\text { - air natural convection } \\
\text { - liquid forced convection } \\
\text { - radiative heat transfer }\end{array}$ \\
\hline
\end{tabular}

Even if the condenser gives rise to less interest in terms of research compared to the evaporator, its design plays an essential role in the conception, design and performance of the LHP. In many cases, the heat sink is imposed by the surrounding environment of the system to cool (water circulation, air or space environment), and thus, it determines the type of heat exchanger. At the condenser, the heat transfer coefficients with the 
surrounding are often small in comparison to the one of condensation, but are partially offset by an extension of the effective heat exchange surface area.

In general, the condenser is sized for the maximum heat flux to be transferred. Under these conditions, the two-phase flow length at the condenser is constrained by the total length of the condenser: the LHP operates in fixed-conductance mode. Therefore, the operating temperature and hence the performance of the LHP are mainly governed by the global heat transfer coefficient at the condenser (Launay et al., 2008). The role of the condensers thermal inertia on the LHP dynamic operation, as startup or oscillating behaviors, is shown very little attention in the literature.

The choice of a condenser configuration is generally guided by the constraints imposed by the LHP integration to the system architecture. If the increase of the heat exchanger external surface has the effect of improving the overall condenser conductance for a given external source and heat flux, it is necessary to ensure that this increase does not come at the expense of system integration. For example, the LHP operation in fixed-conductance mode at high heat flux implies that the reservoir capacity can at least contain the internal volume of the condensation region (tube, annular space) for an optimal use of the condenser. Therefore, reducing the condenser internal volume by adjusting the length or diameter of the tube has a direct effect on the miniaturization of the E/CC.

\subsection{Vapor and liquid lines}

The sizing of the liquid and vapor lines should meet various requirements:

- (i) The wall thickness depends on the tube material and is sized to accommodate the variations of the working fluid pressure;

- (ii) The tube lengths are generally defined or imposed by the positions of the heat source (evaporator) and the heat sink (condenser);

- (iii) The diameters of the liquid and vapor lines are then the only adjustable parameters. The sizing of the tube diameter in a contrary way acts on the performance of the LHP and on its integration to the system. Large diameters tend to reduce the pressure drop along the LHP, therefore, limit the parasitic heat flux between the evaporator and the reservoir, and thereby improving the LHP performance. Diameters of small dimensions contribute to a better integration of LHP by the flexibility of the tubes and by a miniaturization of the E/CC. Indeed, the reservoir must contain not only the volume of the condenser, but also the volume of the vapor line (Maydanik, 2004).

In the literature, the line length varies between $0.05 \mathrm{~m}$ and $5 \mathrm{~m}$, with diameters ranging between 1.2 and $6.35 \mathrm{~mm}$. For a LHP, the vapor line diameter is generally higher or equal to the liquid line one.

\section{EXPERIMENTAL RESULTS}

As indicated in Table 1, various designs of LHP were developed and tested over the past 10 years. It appears that the objectives of most of the experimental investigations are to characterize the LHP thermal performance, or to study the LHP thermal behaviors at the start-up, or during a test of power cycling. Some of these studies analyze the effect of certain parameters, such as the fluid charge, the working fluid nature, the position of the evaporator from the reservoir and the condenser, and the capillary structure on the LHP behaviors. A review of the parameter influence on the LHP operation has been presented by Launay et al. (2007b). In the following section, a synthesis of results on LHP performances at steady-state, and observations related to the LHP dynamic behaviours, as start-up or oscillating behaviours, are presented.

\subsection{Instrumentation}

The Characterization of the performance and the dynamic behavior of a LHP is determined from some sensors implemented on the system.

The heat flux dissipated by the heating element is obtained from the electrical measurements (current, voltage, resistance), while the one, which is transferred to the cold source, is rarely determined. The extracted heat flux was determined by Celata et al. (2010) from the measurements of mass flow rate and the temperature difference of the secondary fluid between the inlet and outlet of the heat exchanger.

The LHP are mostly instrumented by a number of non-intrusive thermocouples up to fifty (or more than 70 for studies on multi-evaporators and multi-condensers). On average, ten temperature measurements are implemented along the LHP. In the literature, there is different representations of the temperature measurements: (i) time evolutions of the temperature at various points of the LHP, (ii) temperature profiles along the LHP for various heat fluxes, (iii) temperature versus heat flux at various points of the LHP. The temperature profile along the condenser allows locating the transition between the condensation region and the region of liquid subcooling. The accuracy of this localization depends on the spacing of the temperature measurements.

In the experimental implementation, there are some measurements of absolute pressure (Ku et al., 2001; Ogushi et al., 2003; Lee et al., 2004; Joung et al., 2010b,a; Singh et al., 2010), and more rarely some measurements of differential pressures (Wrenn et al., 1999; Ku et al., 2001). A few experimental studies in the literature provide direct observations of some parts of the LHP. Cimbala et al. (2004) used neutron radiographic images to visualize the liquid and vapor phase distribution along the LHP tubing. Wang and Nikanpour (2007) developed a special design LHP made of transparent windows in the compensation chamber and FEP clear tubes in order to view the local fluid flow and phase changes. d'Entremont and Ochterbeck (2009) used a borescope inserted through the compensation chamber to capture two-phase conditions into the evaporator core. Li et al. (2010a) used an IR metrology to deduce the temperature distribution at the E/CC component. Launay and Mekni (2010) have developed a LHP, which is specifically designed to follow the vapor and liquid flows all along the LHP, from the vapor line until the evaporation front position inside the capillary structure, based on visible and IR visualizations.

\subsection{Steady-state operation and performance indicators}

In steady-state, various LHP operating characteristics have been experimentally observed. They are usually defined by the operating temperature trends. The LHP operating temperature versus the heat load may be Ushaped, flattened, or may increase linearly with the heat flux. Two main LHP operating modes have been noted in the literature, cited as variable and fixed conductance modes. These modes are correlated to the condenser heat transfer distribution (Launay et al., 2008), one part being used for condensation while the other for the liquid flow subcooling. The transition between these two operating modes is dependent on the heat transfer distribution at the E/CC and on the global heat transfer in two-phase flow region in the condenser. According to the experimental results, it is difficult to predict the shape of the LHP operating curve, because heat leak at the the evaporator/reservoir is strongly influenced by the E/CC design (wall materials and wick characteristics). U-shaped curves have been most often observed for metal capillary wicks, with ammonia as the working fluid (Maydanik, 2004; Chen et al., 2006) and when the temperature difference between the sink and the ambient is large, whereas curves with flattened shapes have been usually observed for low-thermalconductivity wicks with low-pressure working fluids such as methanol, ethanol, or acetone (Boo and Chung, 2004; Riehl and Dutra, 2005).

The LHP performances are usually characterized by the resistance 
$R_{L H P}$ defined by the equation:

$$
R_{L H P}=\frac{T_{E}-T_{\text {Sink }}}{Q_{\text {load }}}
$$

where $T_{E}$ and $T_{\text {Sink }}$ are the temperatures of the heat source and the heat sink, respectively, and $Q_{\text {load }}$ is the total heat load.

$R_{L H P}$ is the resistance of the overall heat transfer system between the heat source and the heat sink, which includes, in the general case, the heat conduction between the heat source and the evaporator through the saddle, the thermo-hydraulic mechanisms of the LHP, and the heat exchange at the cold source. According to the many possible configurations of the LHP integration as presented in Appendix A from the review of the LHP experimental studies, the LHP performances depend on a number of parameters that makes the comparison between them difficult.

In order to analyze the efficiency of the various thermal links of the LHP integration system, $R_{L H P}$ may be decomposed into two terms:

$$
R_{L H P}=\frac{T_{E}-T_{v}}{Q_{\text {load }}}+\frac{T_{C}-T_{\text {Sink }}}{Q_{\text {load }}}=R_{E}+R_{\text {Sink }}
$$

where $T_{v}$ and $T_{C}$ are the temperatures of the fluid saturation at the evaporator and at the condenser, respectively, and assuming the temperature difference $\left(T_{v}-T_{C}\right)$ small compared to other ones. $R_{E}$ and $R_{S i n k}$ characterize the efficiency of the heat transfer in the evaporator (wall conduction and evaporation in the porous wick, see section 3.2) and of the condenser, respectively.

The inherent efficiency of the thermo-hydraulic mechanisms in the LHP (ie not including the external heat exchange of the heat sink), may be obtained from the measurement of working fluid temperature at the condenser output $T_{C, o}$. The value of $T_{C, o}$ provides information on the mode of the LHP operation. A value of $T_{C, o}$ near $T_{\text {sink }}$ means that the LHP is operating in variable conductance mode. The LHP performances are then related to the thermal-hydraulic transfers within the LHP, and particularly at the E/CC. A value of $T_{C, o}$ above $T_{\text {sink }}$ indicates that the LHP is operating in fixed conductance mode. Consequently, the LHP performances become dependent on the condenser efficiency.

The efficiency of the LHP can then be characterized by the equation:

$$
R_{L H P_{2}}=\frac{T_{E}-T_{C, o}}{Q_{\text {load }}}=R_{E}+\frac{T_{C}-T_{C, o}}{Q_{\text {load }}}
$$

$R_{L P_{2}}$ is equal to $R_{L H P}$ in variable conductance mode, whereas it differs perceptibly in fixed conductance mode. $R_{L H P_{2}}$ allows to compare the performances of the various design LHP independently from that of the heat sink. Thus, a minimum of five measures for the temperature $\left(T_{C}, T_{\text {sat }}, T_{\text {Sink }}, T_{C, o}\right.$ and $\left.T_{A m b}\right)$ and one for the heat load $Q_{\text {load }}$ are necessary to determine the resistance $R_{E}, R_{L H P}$ et $R_{L H P_{2}}$ in order to deduce the performance of the individual thermal links of the heat transfer system separately. It will be interesting to divide the LHP resistances by the evaporator surface area in order that the LHP performance takes into account the LHP miniaturization versus the heat load the LHP has to transfer.

According to the review of the experimental results of the LHP literature (See Tables of Appendix A), the resistance $R_{L H P}$ is most of the time specified, whether from the value given by the authors, or deduced from the measures of the study. The resistance $R_{E}$ is less frequently indicated, and most of the time, this value has been deduced from the presented measures. The measure of the working fluid at the condenser outlet $T_{C, o}$ is rarely given, except in some studies for which the authors present the temperature profile along the LHP for various heat fluxes. That's explain why the resistance $R_{L H P_{2}}$ is rarely indicated in the Tables of Appendix A.

It would be rash to make a precise analysis of the LHP performance and attempt to identify the parameters (porous, vapor channel position, bayonet, secondary wick, etc.) that affect the performance with the only value of $R_{L H P}$. Indeed, a "good" E/CC combined with a "bad" condenser would tend to the only conclusion that the LHP has lower performance. On the other hand, this resistance $R_{L H P}$ would then be only slightly useful for developing knowledge about the LHP operation.

\subsection{Analysis of experimental results in transient state}

Start-ups As compared to the capillary pump loop (CPL), which requires pre-conditioning of the loop prior to start-up, the LHP can start directly by applying heat load to the evaporator: LHP is called a selfstarting two-phase heat transport device. This specificity is achieved through the presence of a hydraulic link that provides continuous supply of liquid between the reservoir and the evaporator. However, selfstart does not necessarily imply a quick and immediate start. The consequences of a delayed start of the LHP with respect to the heat flux input may induce stresses that can damage the operating system to cool. Under certain conditions, the LHP may not even start. It is therefore necessary to understand the various mechanisms that interact during the start-up step and to highlight the parameters that influence its characteristics.

Many studies have been conducted on the experimental characterization of the LHP start-up for various operating conditions. The LHP start-up is for most of the time identified by a rapid increase in the temperatures at the vapor line and, in particular, at the condenser inlet. The sharp temperature increase is the result of a shift of the vapor from the evaporator, where vapor is generated, to the condenser. It takes a certain delay between the heat flux input at the evaporator and the LHP startup. The delay before the LHP start-up (onset) depends on a number of parameters that have been listed by Mishkinis et al. (2004): 1/ Liquid and vapour distribution in evaporator and compensation chamber (working fluid inventory, pre-test histories, orientation, etc.); 2/ LHP element geometry: vapor groove design, wick characteristics, etc.; 3/ Heat input power: start-up is usually more reliable and has small temperature overshoot at high input power; 4/ Heat sink temperature; 5/ Thermophysical and chemical properties of the working fluid: effect on the temperature overshoot; 6/ Ambient conditions and thermal insulation of LHP components; 7/ Non-condensed gas (NCG) presence and amount: NCG can influence boiling process in vapor grooves and promote start-up but NCG can also prevent start-up if it is collected in the wick or/and the evaporator wick core (Baumann et al., 1999); 8/ Evaporator mass: high thermal mass may lead to higher overshoot prior to start-up.

This initial phase of heating before the onset of the LHP has not only an effect on the start-up characteristics, but also on the system behavior after the start-up conditions. By LHP startup characteristics, we note, in particular, $1 /$ the required minimum heat flux to induce the LHP start-up, and $2 /$ the overheating of the evaporator wall, compared to the ambient and heat sink temperatures, previously the LHP onset for various operating conditions. The maximum heat flux rate could also become a feature of startup characteristics because it could cause sudden dry-out of the thermo-capillary pump.

As a consequence of these different startup characteristics, various residual effects on the LHP operation in steady state have been reported in the literature (Ku, 1999; Zhang et al., 2004; Huang et al., 2009). For example, Huang et al. (2009) observed, following the LHP start-up for different heat flux, 4 modes of LHP behavior in steady-state: 1 / failure mode if the heat flux is too low, 2 / oscillating mode: continuous oscillation of the operating temperature, 3 / overshoot mode: peak of temperature at the onset of the LHP, 4 / and the normal mode: continuous increase in the operating temperature until steady state.

The main explanations of the LHP start-up characteristics are intimately related to the fluid distribution in the LHP, and especially in the E/CC, at the initial state. There are four possible situations of the liquid/vapor states inside the evaporator/compensation chamber prior to start-up, as shown in Fig. 8 (Maidanik et al., 1995). Also shown in the figure are temperature profiles of the compensation chamber $T_{C C}$ and the 
evaporator $T_{E}$ for each situation from the time the power is applied to the evaporator. It needs to be emphasized that the temperature profiles subsequent to start-up are functions of the heat leak from the evaporator to the compensation chamber and the initial liquid line temperature. Based on the experimental studies, three main factors affect the LHP start-up: 1/ the liquid charge in the vapor grooves: if the evaporator grooves are completely liquid filled, a superheat is required to initiate nucleate boiling; if the vapor grooves already contain vapor, liquid will evaporate as soon as power is applied without any superheat requirement. 2/ the liquid charge in the evaporator core: if the evaporator core is liquid filled, the heat leak from the evaporator to the compensation chamber is minimal since heat is transmitted by conduction through the evaporator container. However, if vapor is present in the evaporator core, heat is transmitted through the primary wick and reaches the vapor immediately. The evaporator core becomes a vapor extension of the compensation chamber. Heat leak therefore increases substantially. 3 / the initial power load: the evaporator heat flux also affects the start-up through interactions with the other two factors.
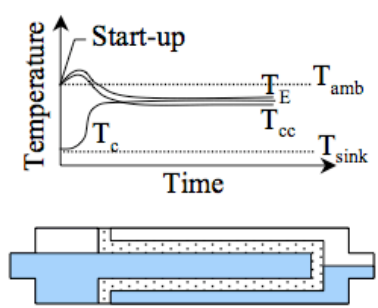

(a) Situation 1
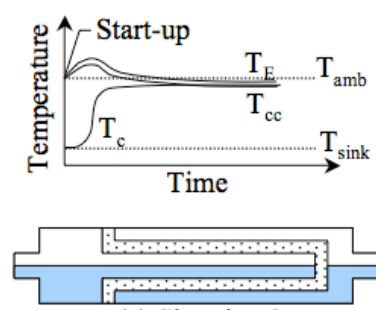

(c) Situation 3
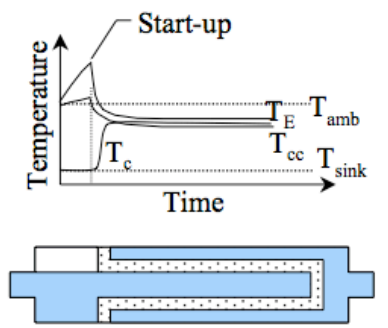

(b) Situation 2
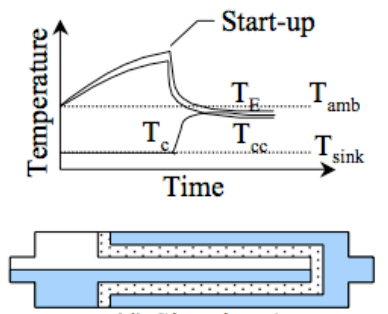

(d) Situation 4
Fig. 8 Schematic of the main physical mechanismes in a LHP

The LHP requires a pressure difference across the wick in order to start. This pressure drop is related to the temperature differential across the wick in accordance with the Clausius-Clapeyron relation (Baumann et al., 1999). With no flow in the system and no heat load on the evaporator, no pressure or temperature gradient will exist across the evaporator wick. As heat is applied to the evaporator wall, a temperature gradient will develop across the wick, thus allowing the system to start pumping. For very low heat loads into the evaporator, the conductive paths to the compensation chamber and through the wick become dominant and the temperature gradient required to develop a sufficient pressure gradient across the wick is elusive. One can conclude that there exists a minimum heat flux for which the LHP may start. Moreover, according to the experimental results of the literature, this demonstration must partly explain the ability of the cylindrical evaporators to start at a lower heat flux rate compared to the flat ones.

The role of the fluid distribution in the E/CC on the LHP startup has been demonstrated from some experimental studies by varying the relative position of the LHP components (the evaporator position relative to the reservoir and the condenser ones) (Boo and Chung, 2004; Chen et al., 2006; d'Entremont and Ochterbeck, 2009; Bai et al., 2009; Celata et al., 2010; Joung et al., 2010b; Lin et al., 2010). In the main cases, the initial distribution of the fluid charge in the $\mathrm{E} / \mathrm{CC}$ is estimated from the compo- nent position. However, the assumption on the fluid charge distribution at the initial state and its role in the start-up seems supported by various visualization methods, which were implemented by different researchers. A particular design LHP, which is composed of two reservoirs with some clear windows, was used by Lin et al. (2010), a borescope was inserted into the evaporator core by d'Entremont and Ochterbeck (2009), and a visualization by neutron radiography was used by Cimbala et al. (2004). d'Entremont and Ochterbeck (2009) observed no significant role in the fluid distribution on the LHP start-up for medium to high heat loads. The effect of the fluid distribution on the start-up has also been studied by $\mathrm{Ku}$ et al. (2001) by combining different component positions and fluid filling ratios. The tests were at the advantage of the highest filling ratio and for the favorable inclinations, for which the evaporator core has a higher probability of being filled. We must keep in mind that some start-up characteristics result from the coupling effects between the fluid distribution and the hydrostatic pressure, which may be induced by the change in position between the LHP components (Joung et al., 2010a).

The pre-history and pre-test conditions are other parameters involved in the fluid distribution at the initial state, and therefore influencing the LHP start-up (Kaya and Ku, 2000; Mishkinis et al., 2004). To this, we must add to the randomness of the superheat temperature for the onset of LHP (Fig. 9 , Mishkinis et al. (2004)). Various techniques of LHP preconditioning were implemented to help them start-up, such as reservoir heating or cooling at a given time (Ref).

According to all these observations, start-up represents perhaps the most complex transient phenomenon in the LHP operation, and the reliable start-up of a LHP is a primary issue of the thermal control.

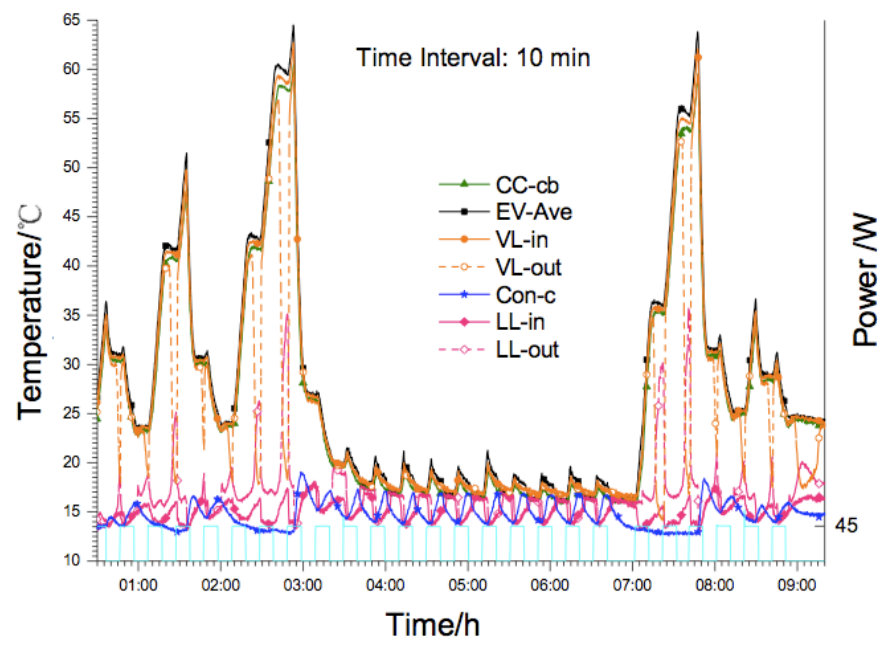

Fig. 9 Patterns of LHP operation during periodical LHP heating (Mishkinis et al., 2004)

Oscillating behaviours Despite the design simplicity and the theoretical operational robustness, various LHP behaviors have been experimentally observed consequently to transient changes, such as start-up or variations in power load and/or sink temperature (Kaya and $\mathrm{Ku}, 2000$ ). Sometimes, the LHP never really reaches a steady-state but instead displays an oscillating behaviors. These oscillating behaviors have been observed for various LHP designs of the literature (see table N) (Rodriguez and Na-Nakornpanom, 2001; Ku, 2003; Ku and Rodriguez, 2003; Mishkinis et al., 2004; Chen et al., 2006; Singh et al., 2008; Celata et al., 2010; Joung et al., 2010b; Li et al., 2010a). Three types of temperature oscillation regimes have been reported in the literature by $\mathrm{Ku}(2003)$ and $\mathrm{Ku}$ and Rodriguez (2003): i) ultra-high frequency (period of about one second or less) temperature oscillations, ii) high frequency (period of few seconds or minutes) low amplitude oscillations caused by the inability of the vapor front to find a stable position inside the condenser, iii) low frequency 
(period of about hours) high amplitude oscillations, which may appear for specific conditions as, for example, large evaporator thermal inertia, low heat load and cold sink temperature compared to the ambient one (Rodriguez and Na-Nakornpanom, 2001; Ku, 2003). As the type i) is usually assumed to be caused by the formation of liquid slugs in the condenser or the vapor line, types ii) and iii) are typically induced by the original complex couplings of the thermal and hydrodynamic mechanisms involved by the interactions and feedback between the loop components.

Chen et al. (2006) studied the influence of the cold source temperature and the relative position of the LHP components (the evaporator position relative to the condenser and the reservoir one's) on the characteristics of the high frequency oscillations (type (ii)). Figure 10 shows, for various LHP configurations, the heat flux ranges for which a temperature oscillating behavior is observed (black surface areas on the histograms). The oscillation frequency varies between 0.01 and $0.05 \mathrm{~Hz}$ and it increases with the heat flux, and the temperature amplitude ranges between 1 and $10 \mathrm{~K}$ at the liquid line inlet, considering the flow direction. Figure 11 shows the temperature oscillation amplitude in various parts of the LHP and for different heat flux when the reservoir is above the evaporator and with a heat sink temperature of $25^{\circ} \mathrm{C}$. The maximum amplitude is about $6 \mathrm{~K}$ at the liquid line inlet (L-line1), and is about $1 \mathrm{~K}$ at the heat source (Evap).

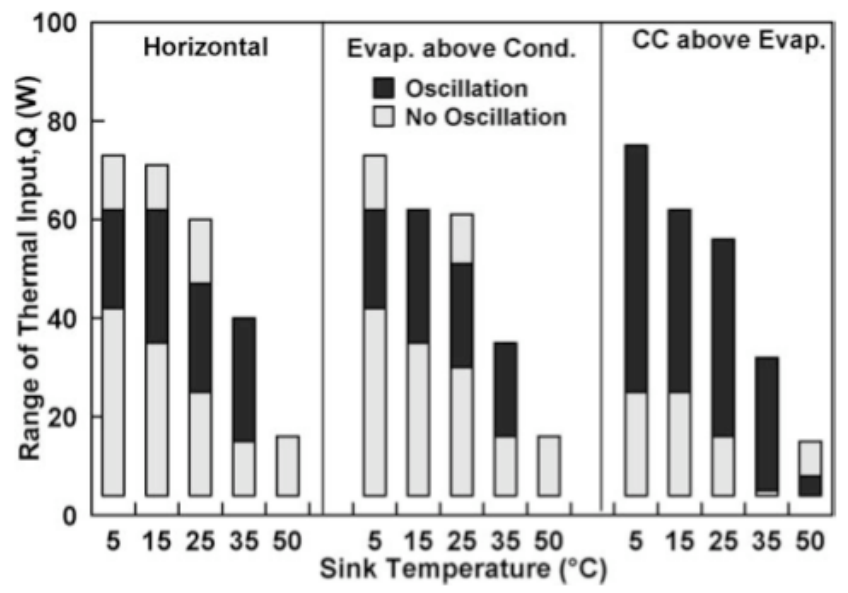

Fig. 10 Heat load range under which the oscillations occur (Chen et al., 2006)

Rodriguez and Na-Nakornpanom (2001) studied the influence of the temperature of the heat sink on the characteristics of the low frequency oscillations (type (iii)). The characteristics of the oscillations are shown in Figs. 12 and Fig. 13 for the amplitude and frequency, respectively. The amplitude varies between 4 and $34 \mathrm{~K}$ and it decreases as the imposed heat flux increases. The frequency varies between $5.10^{-5}$ and $4.10^{-4} \mathrm{~Hz}$ and it increases with the heat flux. In general, lower heat load and sink temperature are conditions that produce oscillations of higher amplitudes with increasing periods. According to the authors, this phenomenon is not affected by initial start-up conditions and it is very stable and repeatable.

\section{CONCLUSION}

In the present work, it has been made an inventory of more than 50 conventional LHP from experimental studies of the literature in the years 1998-2010. Although the evaporator/compensation chamber (E/CC) of cylindrical design were initially preferred by the researchers, a number of new E/CC configurations have been proposed during the years 20092010. A classification of E/CC designs in three main class are proposed: (i) cylindrical; (ii) flat with the reservoir located in the extension of the

\section{$\mathrm{CC}$ above Evap./Tsink $=25^{\circ} \mathrm{C}$}

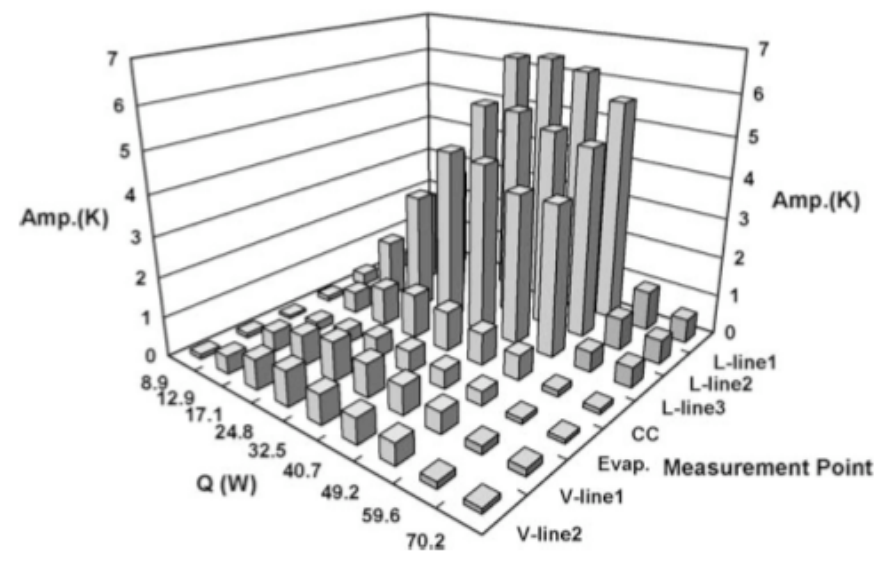

Fig. 11 Amplitude of the temperature oscillations at various positions along the loop for different heat loads (Chen et al., 2006)
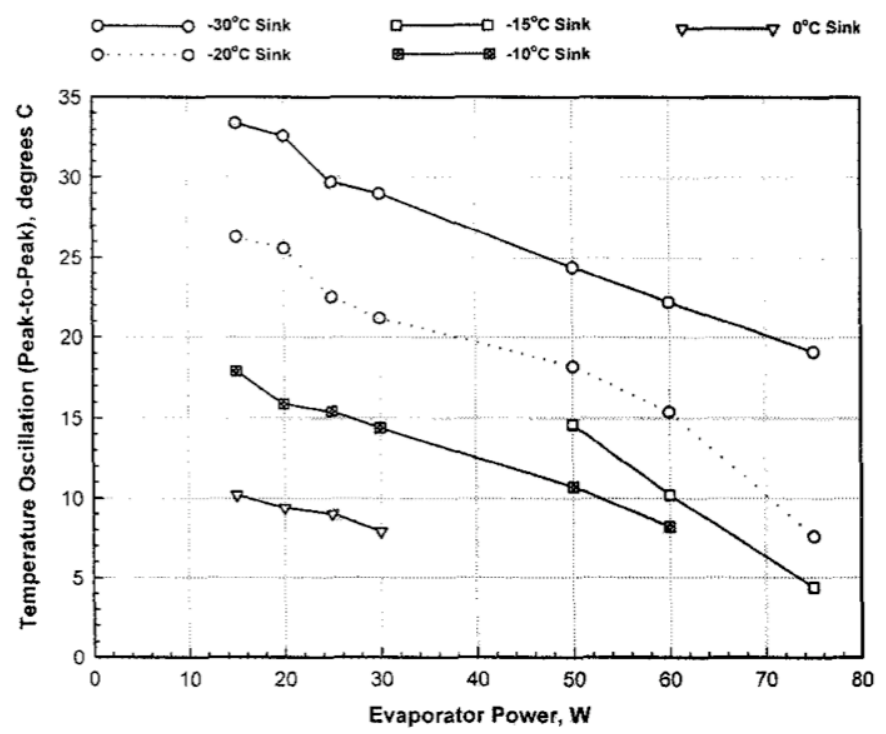

Fig. 12 Transient temperature amplitudes with low frequency oscillations (Rodriguez and Na-Nakornpanom, 2001)

evaporator; (iii) flat with the reservoir located in the thickness of the evaporator. The diversity of these various geometries of $\mathrm{E} / \mathrm{CC}$ is a response to expanding applications of the LHP with the issue of miniaturization for a better implementation within a 3D architecture of the electronic modules, and for the issue of higher dissipated heat flux rates. The detailed description of the LHP components is presented in a certain order that might look like a LHP design procedure for a given application.

From the review of the LHP experimental studies, it has been noticed that some useful LHP characteristics are sometimes missing, as the thermal-hydraulic link between the evaporator and the reservoir, the porous wick characteristics, or the vapor channel configuration. Questions arise concerning the definition or characterization of the pore diameter of the porous wicks. Some studies only focused on the characterization of the global LHP thermal resistance $R_{L H P}$. This resistance concerns the overall heat transfer system between the heat source and the heat sink, which includes, in the general case, the heat conduction between the heat source and the evaporator through the saddle, the thermal-hydraulic mechanismes of the LHP, and the heat exchange at the heat sink. In the present paper, other criteria of LHP performance are proposed in order 


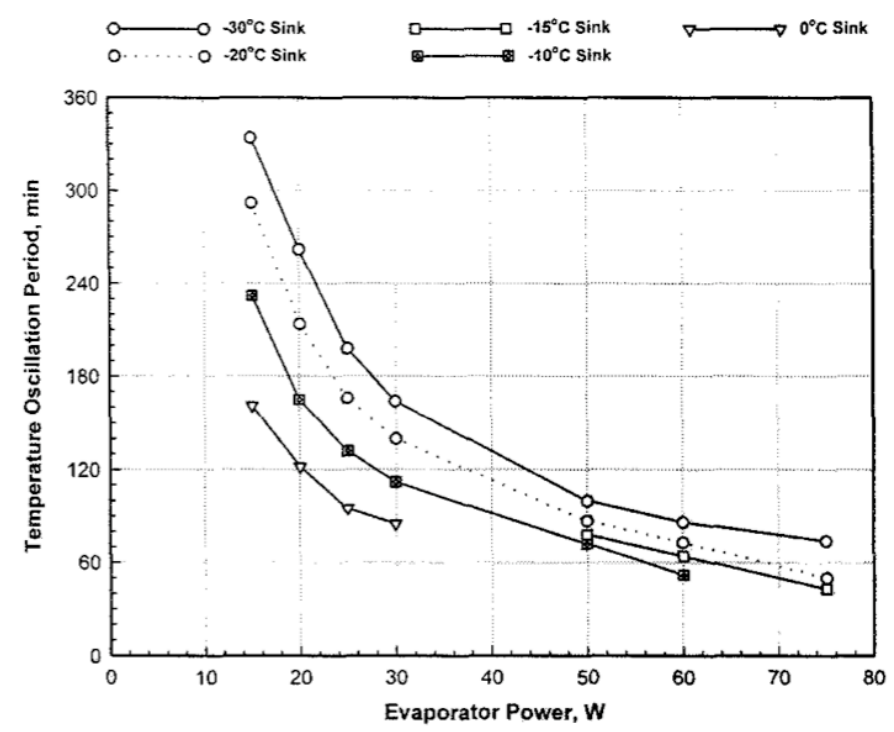

Fig. 13 Transient temperature period for low frequency oscillations (Rodriguez and Na-Nakornpanom, 2001)

better define the effect of each thermal link characterizing the LHP system.

Particular attention in LHP experimental studies to inform the different elements mentioned in this review, while maintening protection of know-how, should promote the development of tools for understanding and predicting the LHP behaviors.

\section{ACKNOWLEDGEMENTS}

The authors would like to thank the French Research Group (GDR SYREDI) working on two-phase cooling systems for the fruitful discussions during meetings.

\section{NOMENCLATURE}

$\begin{array}{ll}k & \text { thermal conductivity }(\mathrm{W} / \mathrm{m} \cdot \mathrm{K}) \\ K & \text { permeability }\left(\mathrm{m}^{2}\right) \\ P & \text { pressure }(P a) \\ P_{c} & \text { critical pressure }(P a) \\ q^{\prime \prime} & \text { heat flux }\left(\mathrm{W} / \mathrm{m}^{2}\right) \\ R & \text { thermal resistance }(\mathrm{K} / \mathrm{W}) \\ t & \text { time }(\mathrm{s}) \\ T & \text { temperature }(\mathrm{K}) \\ \text { Greek Symbols } \\ \oslash & \text { diameter }(\mathrm{m}) \\ \epsilon & \text { porosity } \\ \rho & \text { density }\left(\mathrm{kg} / \mathrm{m}^{3}\right) \\ \text { Subscripts } & \\ 0 & \text { initial condition } \\ \text { Amb } & \text { ambient } \\ C & \text { condenser } \\ C C & \text { compensation chamber } \\ C, o & \text { condenser outlet } \\ E & \text { evaporator } \\ \text { eff } & \text { effective } \\ h & \text { hydraulic } \\ l o a d & \text { load } \\ \text { max } & \text { maximal } \\ p & \text { pore } \\ R & \text { reservoir }\end{array}$

$\begin{array}{ll}\text { sat } & \text { sat } \\ \text { Sink } & \text { Sink } \\ v & \text { vapor } \\ w & \text { wick } \\ \text { wall } & \text { wall }\end{array}$

\section{REFERENCES}

Adoni, A.A., Ambirajan, A., Jasvanth, V.S., Kumar, D., and Dutta, P., 2009, "Effects of Mass of Charge on Loop Heat Pipe Operational Characteristics," Journal of Thermophysics and Heat Transfer, 23(2), 346-355, doi:10.2514/1.41618.

Altman, E.I., Mukminova, M.I., , and Smirnov, H.F., 2002, "The Loop Heat Pipe Evaporators Theoretical Analysis," Proceedings of the 12th International Heat Pipe Conference, 159-164, Russia.

Bai, L.Z., Lin, G.P., Zhang, H.X., and Wen, D.S., 2009, "Mathematical modeling of steady-state operation of a loop heat pipe," Applied Thermal Engineering, 29(13), 2643-2654, doi:10.1016/j.applthermaleng.2008.12.040.

Baker, C.L., Bienert, W.B., and Ducao, A.S., 1998, "Loop Heat Pipe Flight Experiment," 28th International Conference On Environmental Systems, SAE paper 981580, 7 p., Danvers, MA, USA.

Baumann, J., Cullimore, B., Yendler, B., and Buchan, E., 1999, "Noncondensible gas, mass, and adverse tilt effects on the start-up of loop heat pipes," International Conference On Environmental Systems, SAE 199901-2048, Denver, CO, USA, doi:DOI: 10.4271/1999-01-2048.

Becker, S., Vershinin, S., Sartre, V., Laurien, E., Bonjour, J., and Maydanik, Y., 2010, "Steady state operation of a copperâĂŞwater LHP with a flat-oval evaporator," Applied Thermal Engineering, (Article In Press), doi:doi:10.1016/j.applthermaleng.2010.02.005.

Boo, J.H., and Chung, W.B., 2004, "Thermal performance of a smallscale loop heat pipe with pp wick," Proceedings of 13th International Heat Pipe Conference, 259-264, Shangai, China.

Celata, G.P., Cumo, M., and Furrer, M., 2010, "Experimental tests of a stainless steel loop heat pipe with flat evaporator," Experimental Thermal and Fluid Science, 34(7), 866-878, doi:10.1016/j.expthermflusci.2010.02.001.

Chen, Y.M., Groll, M., Mertz, R., Maydanik, Y.F., and Vershinin, S.V., 2006, "Steady-state and transient performance of a miniature loop heat pipe," International Journal of Thermal Sciences, 45(11), 1084-1090, doi:10.1016/j.ijthermalsci.2006.02.003.

Cheung, K.H., Hoang, T., Ku, J., and Kaya, T., 1998, "Thermal performance and operational characteristics of loop heat pipe (NRL LHP)," 28th International Conference On Environmental Systems, Danvers, MA, USA, doi:DOI: 10.4271/981813.

Choi, J., Sung, B., Nguyen, X.H., J., Y., and Kim, C., 2010, “A study on the operation stability improvement of mLHP," Proceedings of 15th International Heat Pipe Conference, Clemson, USA.

Chuang, P.Y.A., 2003, An improved steady-state model of loop heat pipes based on experimental and theoretical analyses, Ph.D. thesis, The Pennsylvania State University.

Cimbala, J.M., Brenizer, J.S., Chuang, A.P.Y., Hanna, S., Conroy, C.T., El-Ganayni, A.A., and Riley, D.R., 2004, "Study of a loop heat pipe using neutron radiography," Applied Radiation and Isotopes, 61(4), 701-705, doi:10.1016/j.apradiso.2004.03.104. 
Delil, A., Baturkin, V., Friedrichson, Y., and Khmelev, 2002, "Experimental results of heat transfer phenomena in a miniature loop heat pipe with a flat evaporator," Proceeding of the 12th International Heat Pipe Conference., 126-133, Moscow, Russia.

Delil, A., Maydanik, Y., and Gerhart, C., 2003, "Development of Different Novel Loop Heat Pipes within the ISTC-1360 Project," International Conference On Environmental Systems, SAE 2003-01-2383, doi:DOI: 10.4271/2003-01-2383.

d'Entremont, B.P., and Ochterbeck, J.M., 2009, "Investigation of Loop Heat Pipe Startup Using Liquid Core Visualization," Ht2008: Proceedings of the Asme Summer Heat Transfer Conference - 2008, Vol 2, 387393.

Figus, C., Le Bray, Y., Bories, S., and Prat, M., 1999, "Heat and mass transfer with phase change in a porous structure partially heated: continuum model and pore network simulations," International Journal of Heat and Mass Transfer, 42(14), 2557-2569, doi:10.1016/S00179310(98)00342-1.

Hoang, T.T., and Ku, J., 2003, "Miniature Loop Heat Pipes for electronic cooling," Proceedings of IPACK03, International Electronic Packaging Technical Conference and Exhibition, Maui, Hawaii, USA.

Hoang, T., O'Connell, T., Ku, J., Butler, C., Swanson, T., and Khrustalev, D., 2003, "Design optimization of a hydrogen advanced Loop Heat Pipe for space-based IR sensor and detector cryocooling," Proceedings of the Society of Photo-Optical Instrumentation Engineers (SPIE), vol. 5172, 86-96, San Diego, CA, USA.

Hsu, C.C., Kang, S.W., and Hou, T.F., 2005, "Performance Testing of Micro Loop Heat Pipes," Tamkang Journal of Science and Engineering, 8(2), 123-132.

Huang, B.J., Huang, H.H., and Liang, T.L., 2009, "System dynamics model and startup behavior of loop heat pipe," Applied Thermal Engineering, 29(14-15), 2999-3005, doi:10.1016/j.applthermaleng.2009.03.015.

Joung, W., Hwang, H., and Lee, J., 2010a, "Experimental study on the operating characteristics of a capillary pumped loop with a flat evaporator," International Journal of Heat and Mass Transfer, 53(1-3), 268-275, doi:10.1016/j.ijheatmasstransfer.2009.09.032.

Joung, W., Yu, T., and Lee, J., 2008, "Experimental study on the loop heat pipe with a planar bifacial wick structure," International Journal of Heat and Mass Transfer, 51(7-8), 1573-1581, doi:10.1016/j.ijheatmasstransfer.2007.07.048.

Joung, W., Yu, T., and Lee, J., 2010b, "Experimental study on the operating characteristics of a flat bifacial evaporator loop heat pipe," International Journal of Heat and Mass Transfer, 53(1-3), 276-285, doi:10.1016/j.ijheatmasstransfer.2009.09.031.

Kaya, T., and Ku, J., 2000, "Performance characteristics of a terrestrial loop heat pipe," 38th Aerospace Sciences Meeting Exhibit, Reno, NV, USA.

Kaya, T., and Goldak, J., 2006, "Numerical analysis of heat and mass transfer in the capillary structure of a loop heat pipe," International Journal of Heat and Mass Transfer, 49(17-18), 3211-3220, doi:10.1016/j.ijheatmasstransfer.2006.01.028.

Ku, J., 1999, "Operating Characteristics of Loop Heat Pipes," International Conference On Environmental Systems, SAE 1999-01-2007, Denver, CO, USA, doi:10.4271/1999-01-2007.
Ku, J., 2003, "High Frequency Low Amplitude Temperature Oscillations in Loop Heat Pipe Operation," International Conference On Environmental Systems, SAE 2003-01-2387, Vancouver, BC, CANADA, doi:10.4271/2003-01-2387.

Ku, J., Ottenstein, L., Rogers, P., and Cheung, K., 2001, "Investigation of Low Power Operation in a Loop Heat Pipe," 31st International Conference On Environmental Systems, SAE 2001-01-2192, Orlando, FL, USA, doi:DOI: 10.4271/2001-01-2192.

Ku, J., and Rodriguez, J.I., 2003, "Low Frequency High Amplitude Temperature Oscillations in Loop Heat Pipe Operation," International Conference On Environmental Systems, SAE 2003-01-2386, Vancouver, BC, CANADA, doi:10.4271/2003-01-2386.

Ku, J., Hoang, T., and O'Connell, T., 2009, "Mathematical Modeling of a Miniature Loop Heat Pipe with two Evaporators and two Condensers," Proceedings of the ASME Summer Heat Transfer Conference, vol. 2, 483494, San Francisco, CA, USA.

Launay, S., Platel, V., Dutour, S., and Joly, J.L., 2007a, “Transient modeling of loop heat pipes for the oscillating. behavior study," Journal of Thermophysics and Heat Transfer, 21(3), 487-495, doi:10.2514/1.26854.

Launay, S., Sartre, V., and Bonjour, J., 2008, "Analytical Model for Characterization of Loop Heat Pipes," Journal of Thermophysics and Heat Transfer, 22(4), 623-631, doi:10.2514/1.37439.

Launay, S., Sartre, V., and Bonjour, J., 2007b, "Parametric analysis of loop heat pipe operation: a literature review," International Journal of Thermal Sciences, 46(7), 621-636, doi:10.1016/j.ijthermalsci.2006.11.007.

Launay, S., and Mekni, N., 2010, "Specifically Designed Loop Heat Pipe for Quantitative Characterization," Proceedings of 15th International Heat Pipe Conference, Clemson, USA.

Launay, S., Sartre, V., and Bonjour, J., 2010, "Selection criteria for fluidic and geometrical parameters of a LHP based on an analytical approach," Proceedings of 15th International Heat Pipe Conference, Clemson, USA.

Lee, W.H., Lee, K.W., Park, K.H., and Lee, K.J., 2004, "Study on working characteristics of loop heat pipe using a sintered metal wick," Proceedings of 13th International Heat Pipe Conference, 265-269, Shangai, China.

Li, J., Wang, D., and Peterson, G., 2010a, "Experimental studies on a high performance compact loop heat pipe with a square flat evaporator," Applied Thermal Engineering, 30, 741âĂŞ-752, doi:10.1016/j.applthermaleng.2009.12.004.

Li, J., Zou, Y., Cheng, L., Singh, R., and Akbarzadeh, A., 2010b, "Effect of fabricating parameters on properties of sintered porous wicks for loop heat pipe," Powder Technology, 204, 241-248, doi:doi:10.1016/j.powtec.2010.08.008.

Lin, G.P., Li, N., Bai, L.Z., and Wen, D.S., 2010, "Experimental investigation of a dual compensation chamber loop heat pipe," International Journal of Heat and Mass Transfer, 53(15-16), 3231-3240, doi:10.1016/j.ijheatmasstransfer.2010.03.003.

Maidanik, Y., and Fershtater, Y., 1997, "Theoretical basis and classification of loop heat pipes and capillary pumped loops," Proceedings of the 10th International Heat Pipe Conference, Stuttgart, Germany.

Maydanik, Y.F., 2005, "Loop heat pipes," Applied Thermal Engineering, 25(5-6), 635-657, doi:10.1016/j.applthermaleng.2004.07.010. 
Maydanik, Y.F., 2004, "Miniature Loop Heat Pipes," Proceedings of 13th International Heat Pipe Conference, 23-35, Shangai, China.

Mishkinis, D., Prado, P., Sanz, R., Torres, A., Merino, A.S., and Tjiptahardja, T., 2010, "Development of Loop Heat Pipe for intermediate temperature range," Proceedings of 15th International Heat Pipe Conference, Clemson, USA.

Mishkinis, D., Wang, G., Nikanpour, D., MacDonald, E., and Kaya, T., 2004, "Steady-state and transient loop heat pipe performance during periodic heating cycles," Proceedings of 13th International Heat Pipe Conference, 71-77, Shanghai, China.

Mo, Q., and Liang, J., 2006, "A novel design and experimental study of a cryogenic loop heat pipe with high heat transfer capability," International Journal of Heat and Mass Transfer, 49, 770-776, doi:10.1016/j.ijheatmasstransfer.2005.08.010.

Mo, S., Hu, P., Cao, J., Chen, Z., Fan, H., and Fei, Y., 2006, "Effective Thermal Conductivity of Moist Porous Sintered Nickel Material," International Journal of Thermophysics, 27(1), 304-313, doi:10.1007/s10765-006-0030-9.

Nagano, H., Fukuyoshi, F., Ogawa, H., and Nagano, H., 2010, "Investigation of a Small Loop Heat Pipe with PTFE Wick," Proceedings of 15th International Heat Pipe Conference, Clemson, USA.

Nagano, H., and Ku, J., 2007, "Capillary limit of a multiple-evaporator and multiple-condenser miniature loop heat pipe," Journal of Thermophysics and Heat Transfer, 21(4), 694-701, doi:10.2514/1.26151.

Nikitkin, M., and Cullimore, B., 1998, "CPL and LHP Technologies: What are the Differences, What are the Similarities?" International Conference On Environmental Systems, SAE 981587, Danvers, MA, USA, doi:10.4271/981587.

Ogushi, T., Yao, A., Xu, J.J., Masumoto, H., and Kawaji, M., 2003, "Heat transport characteristics of flexible looped heat pipe under microgravity condition," Heat Transfer - Asian Research, 32, 381-390, doi:10.1002/htj.10092.

Pastukhov, V.G., Maidanik, Y.F., Vershinin, C.V., and Korukov, M.A., 2003, "Miniature loop heat pipes for electronics cooling," Applied Thermal Engineering, 23(9), 1125-1135, doi:10.1016/S13594311(03)00046-2.

Pastukhov, V.G., and Maydanik, Y.F., 2007, "Low-noise cooling system for PC on the base of loop heat pipes," Applied Thermal Engineering, 27, 894-901, doi:10.1016/j.applthermaleng.2006.09.003.

Pauken, M., and Rodriguez, J.I., 2000, "Performance Characterization and Model Verification of a Loop Heat Pipe," International Conference On Environmental Systems, SAE 2000-01-2317, Toulouse, FRANCE, doi:10.4271/2000-01-2317.

Reay, D.A., and Kew, P.A., 2006, Heat Pipes: Theory, Design And Applications, 5th Edition, Butterworth Heinemann.

Riehl, R.R., and Dutra, T., 2005, "Development of an experimental loop heat pipe for application in future space missions," Applied Thermal Engineering, 25(1), 101-112, doi:10.1016/j.applthermaleng.2004.05.010.

Riehl, R.R., and Siqueira, T.C.P.A., 2006, "Heat transport capability and compensation chamber influence in loop heat pipes performance," Applied Thermal Engineering, 26(11-12), 1158-1168, doi:10.1016/j.applthermaleng.2005.10.037.
Rodriguez, J.I., and Na-Nakornpanom, A., 2001, "Investigation of Transient Temperature Oscillations of a Propylene Loop Heat Pipe," 31st International Conference On Environmental Systems, SAE 2001-01-2235, Orlando, FL, USA, doi:10.4271/2001-01-2235.

Singh, R., Akbarzadeh, A., and Mochizuki, M., 2008, "Operational characteristics of a miniature loop heat pipe with flat evaporator," International Journal of Thermal Sciences, 47(11), 1504-1515, doi:10.1016/j.ijthermalsci.2007.12.013.

Singh, R., Akbarzadeh, A., and Mochizuki, M., 2010, "Operational characteristics of the miniature loop heat pipe with non-condensable gases," International Journal of Heat and Mass Transfer, 53(17-18), 3471-3482, doi:10.1016/j.ijheatmasstransfer.2010.04.008.

Vershinin, S.V., and Maydanik, Y.F., 2007a, "Hysteresis phenomena in loop heat pipes," Applied Thermal Engineering, 27(5-6), 962-968, doi:10.1016/j.applthermaleng.2006.08.016.

Vershinin, S.V., and Maydanik, Y.F., 2007b, "Investigation of pulsations of the operating temperature in a miniature loop heat pipe," International Journal of Heat and Mass Transfer, 50(25-26), 5232-5240, doi:10.1016/j.ijheatmasstransfer.2007.06.024.

Vlassov, V.V., and Riehl, R.R., 2008, "Mathematical model of a loop heat pipe with cylindrical evaporator and integrated reservoir," Applied Thermal Engineering, 28, 942-954, doi:10.1016/j.applthermaleng.2007.07.016.

Wang, G., and Nikanpour, D., 2007, "Visual Observations of Flow and Phase Phenomena in Loop Heat Pipes," AIP Conference Proceedings, 914, 291-298, doi:10.1063/1.2747444.

Wrenn, K.R., Krein, S.J., Hoang, T.T., and Allen, R.D., 1999, "Verification of a Transient Loop Heat Pipe Model," International Conference On Environmental Systems, SAE 1999-01-2010, Denver, CO, USA, doi:10.4271/1999-01-2010.

Xin, G., Cui, K., Zou, Y., and Cheng, L., 2010, "Reduction of effective thermal conductivity for sintered LHP wicks," International Journal of Heat and Mass Transfer, 53, 2932-2934, doi:10.1016/j.ijheatmasstransfer.2010.02.056.

Yeh, C.C., Chen, C.N., and Chen, Y.M., 2009, "Heat transfer analysis of a loop heat pipe with biporous wicks," International Journal of Heat and Mass Transfer, 52(19-20), 4426-4434, doi:10.1016/j.ijheatmasstransfer.2009.03.059.

Yeh, C.C., Liu, B.H., and Chen, Y.M., 2008, "A study of loop heat pipe with biporous wicks," Heat and Mass Transfer, 44(12), 1537-1547, doi:10.1007/s00231-008-0387-3.

Zhang, H.X., Ding, T., Shao, X.G., Lin, G.P., Sudakov, R., and Maidanik, Y., 2004, "Effects of start-up on operation of loop heat pipes," Proceedings of 13th International Heat Pipe Conference, 133-138, Shangai, China.

\section{APPENDIX A: SYNTHESIS OF CHARACTERISTICS AND PERFORMANCES OF VARIOUS LOOP HEAT PIPES}




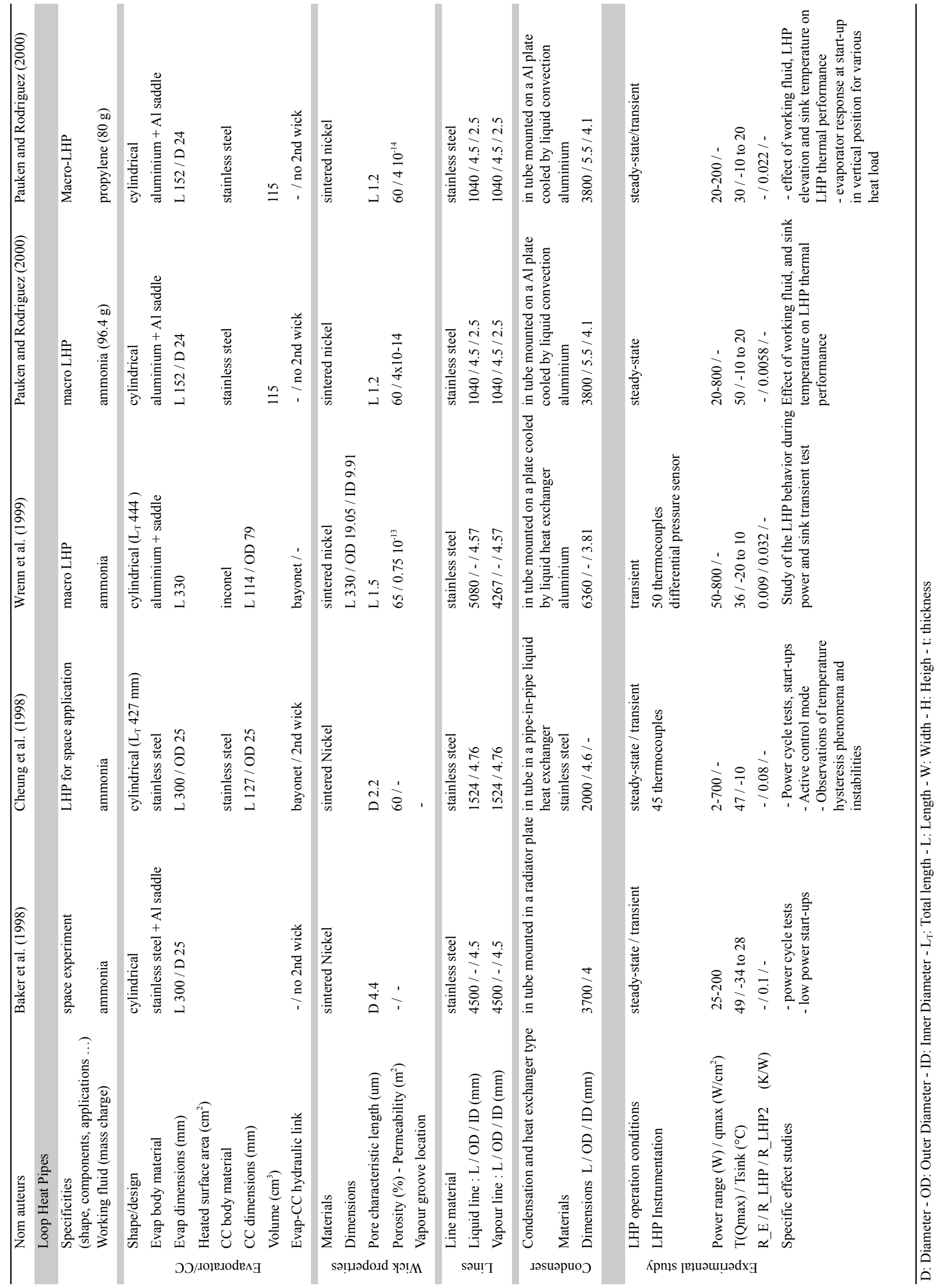




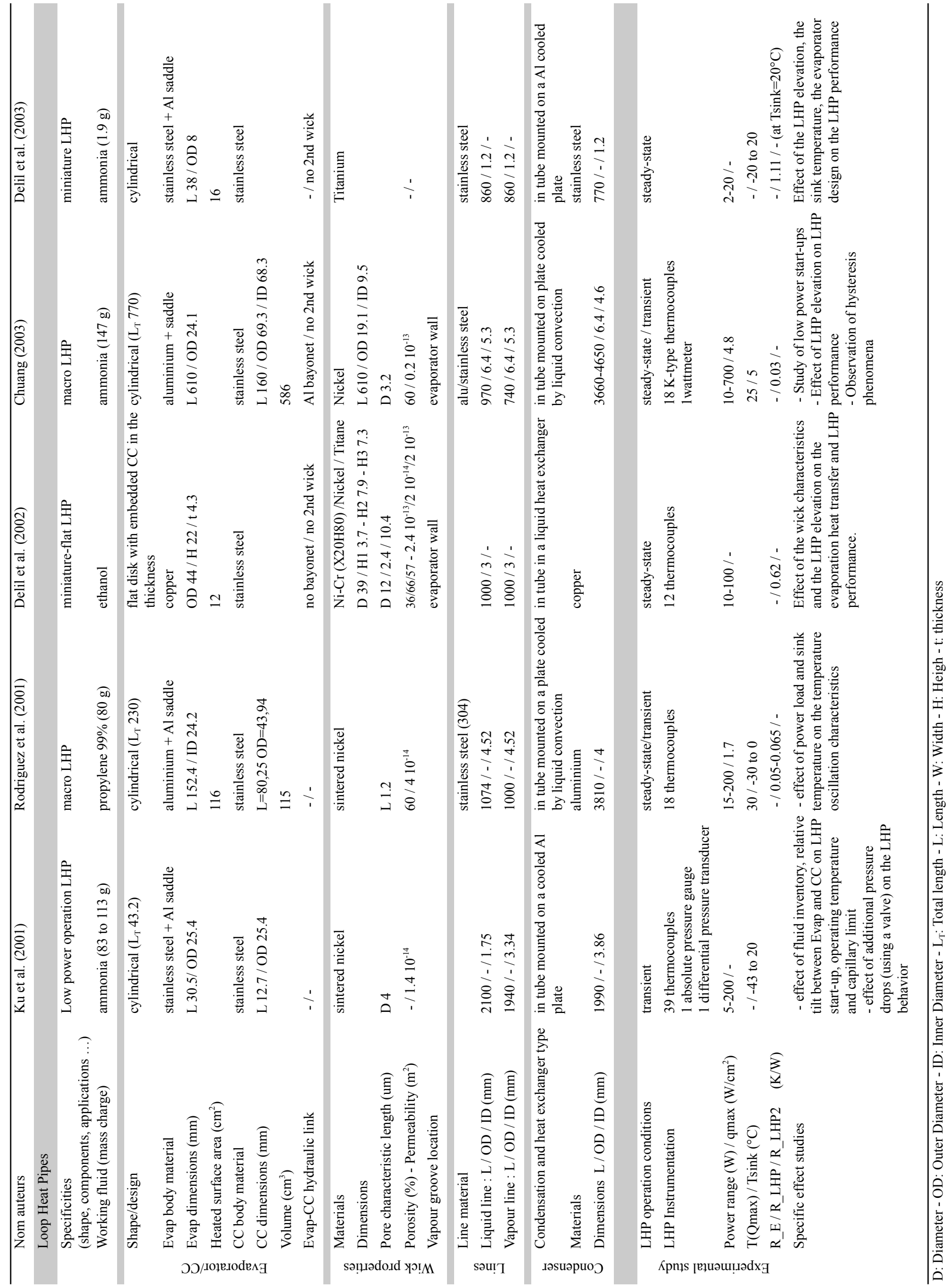




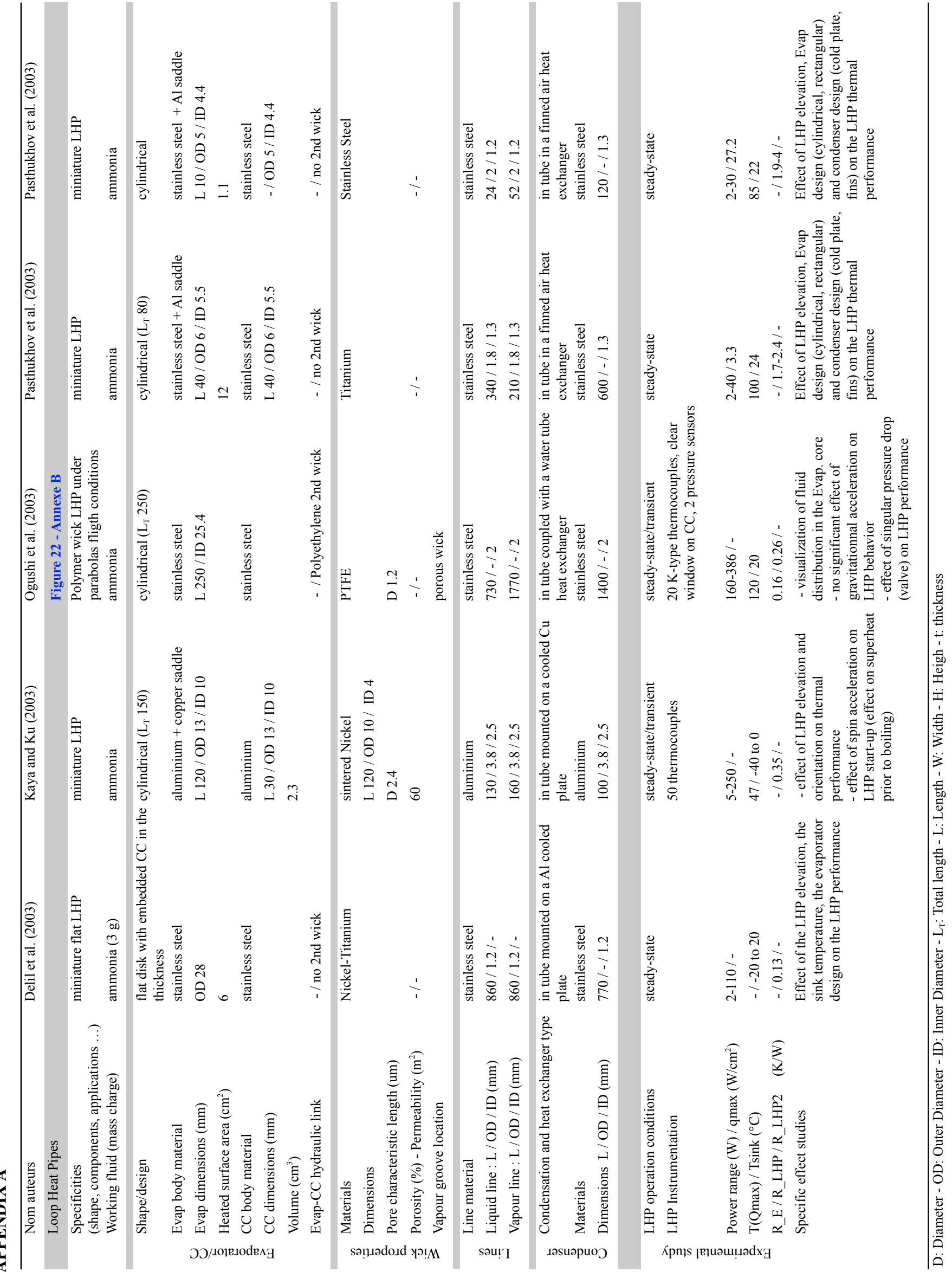




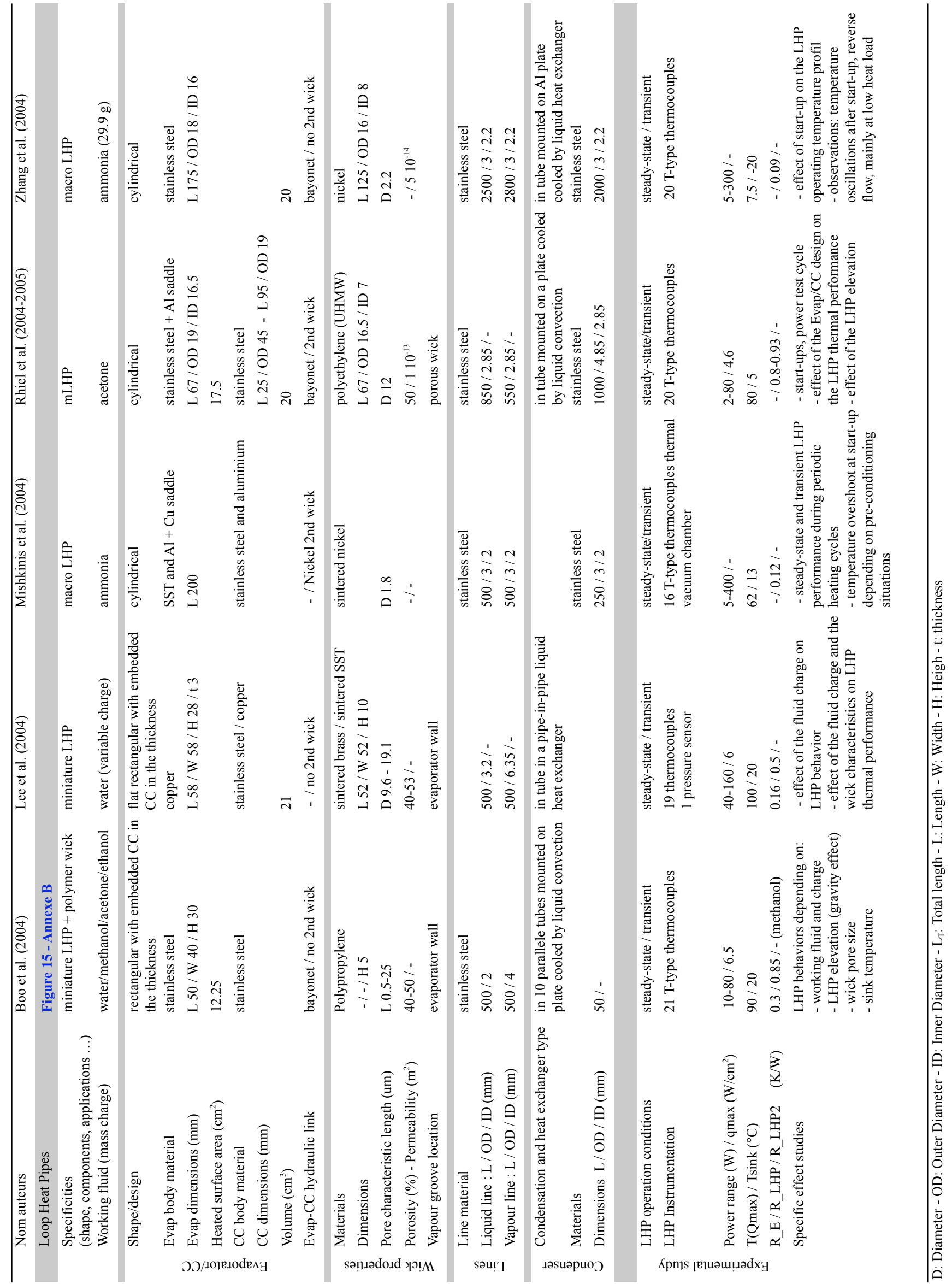




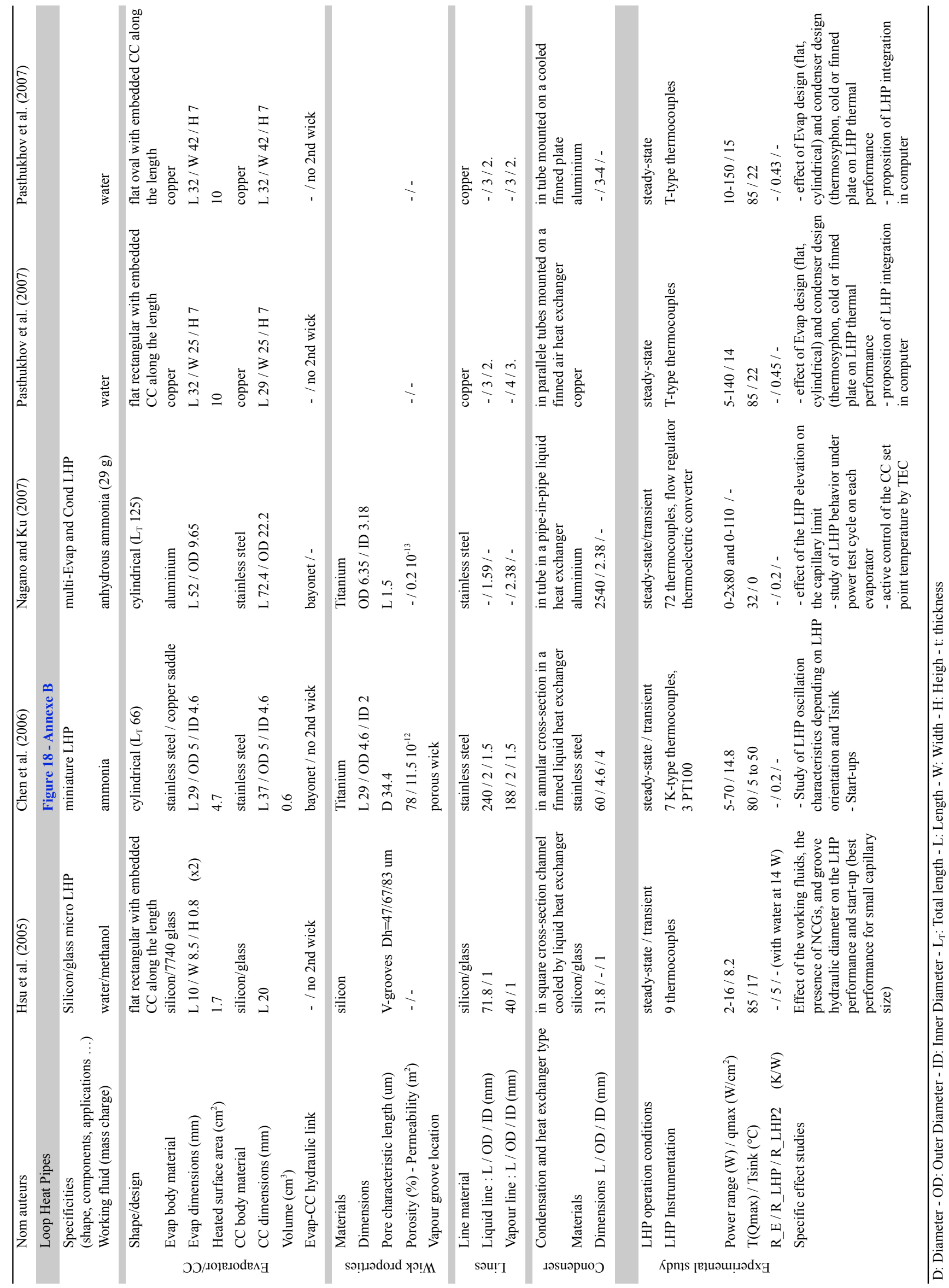




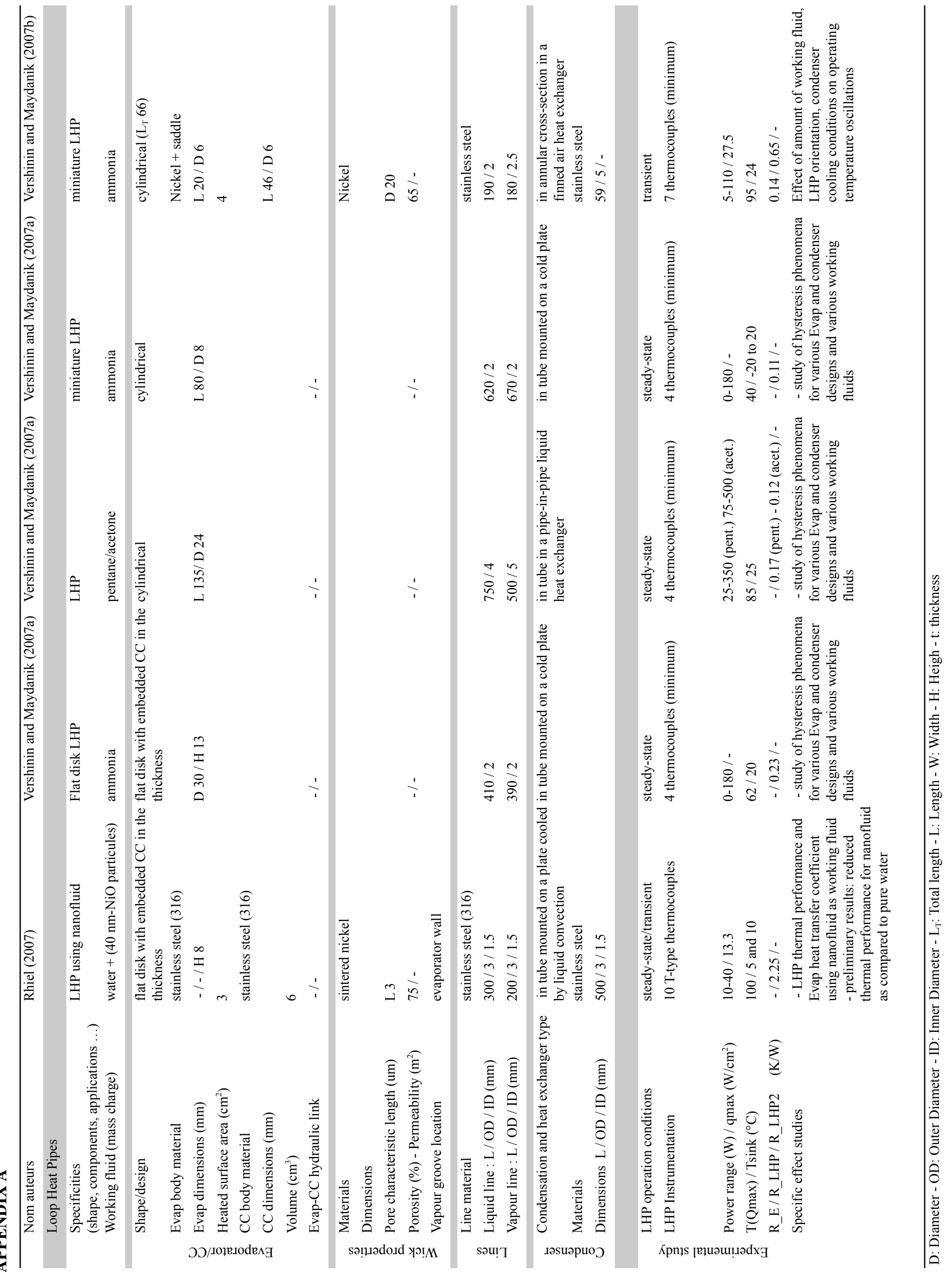




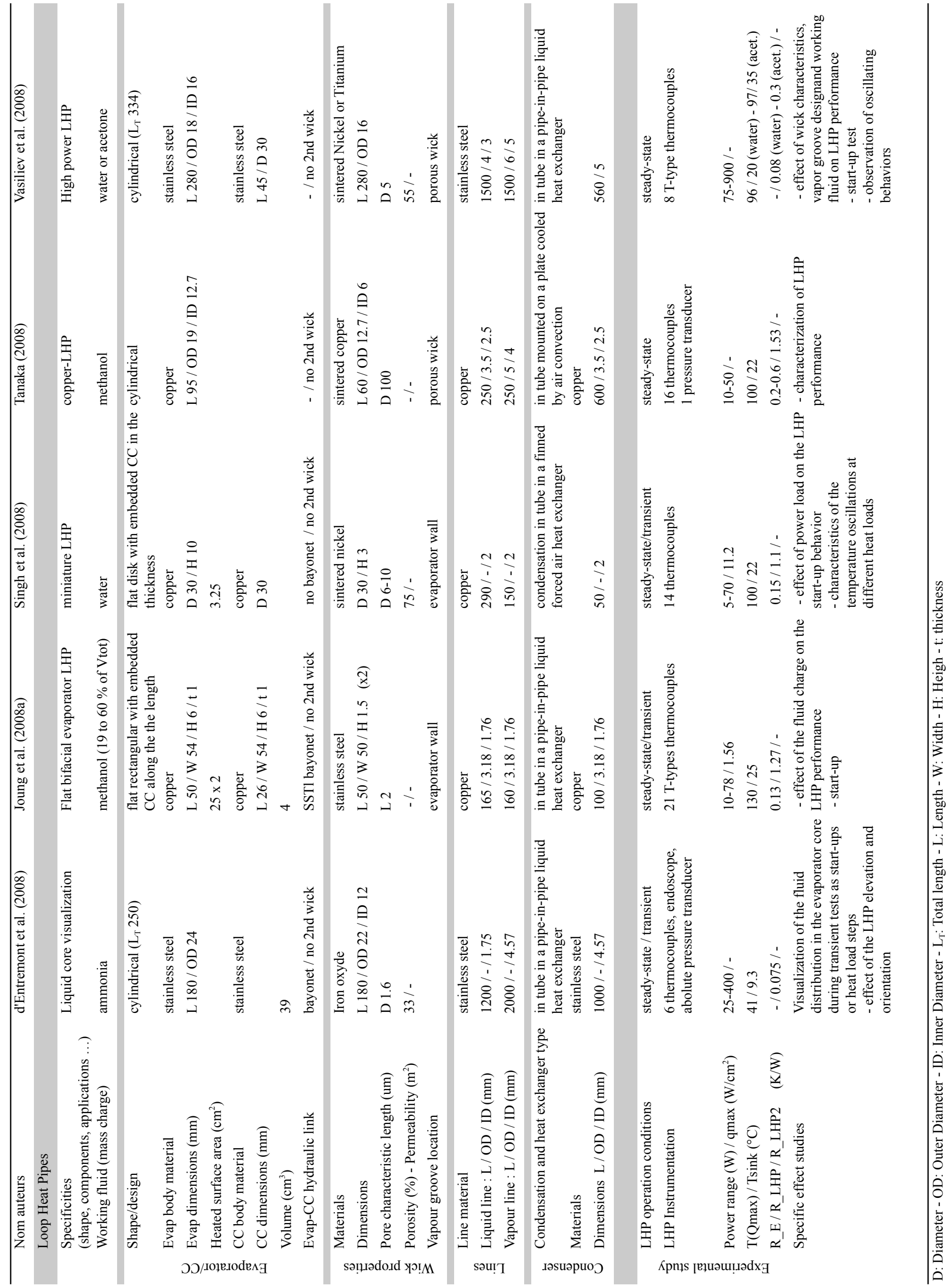



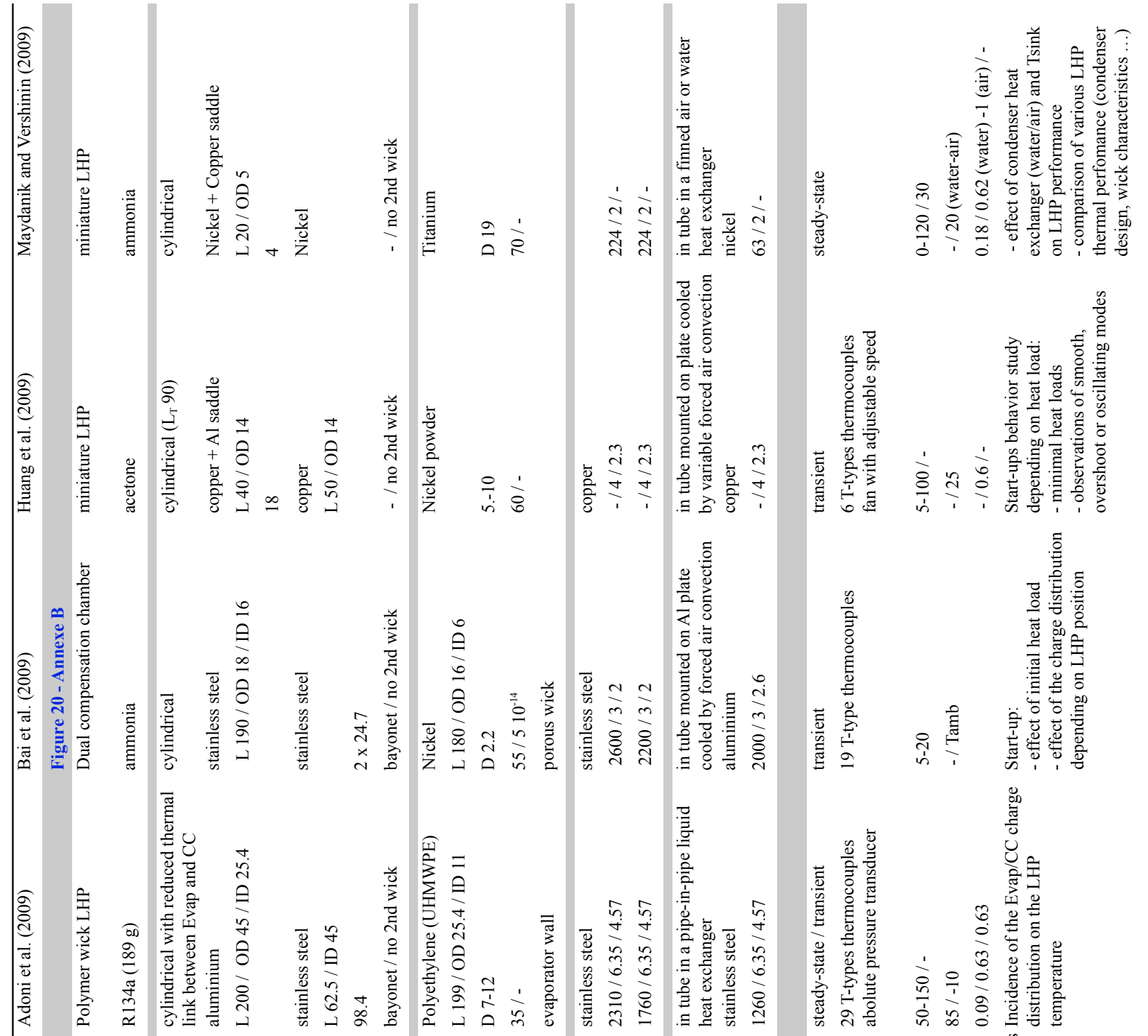

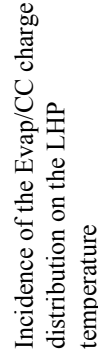

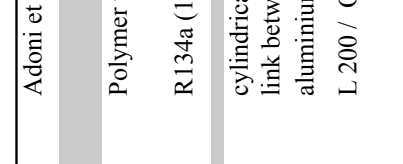

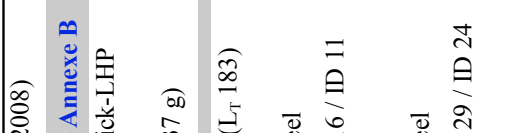
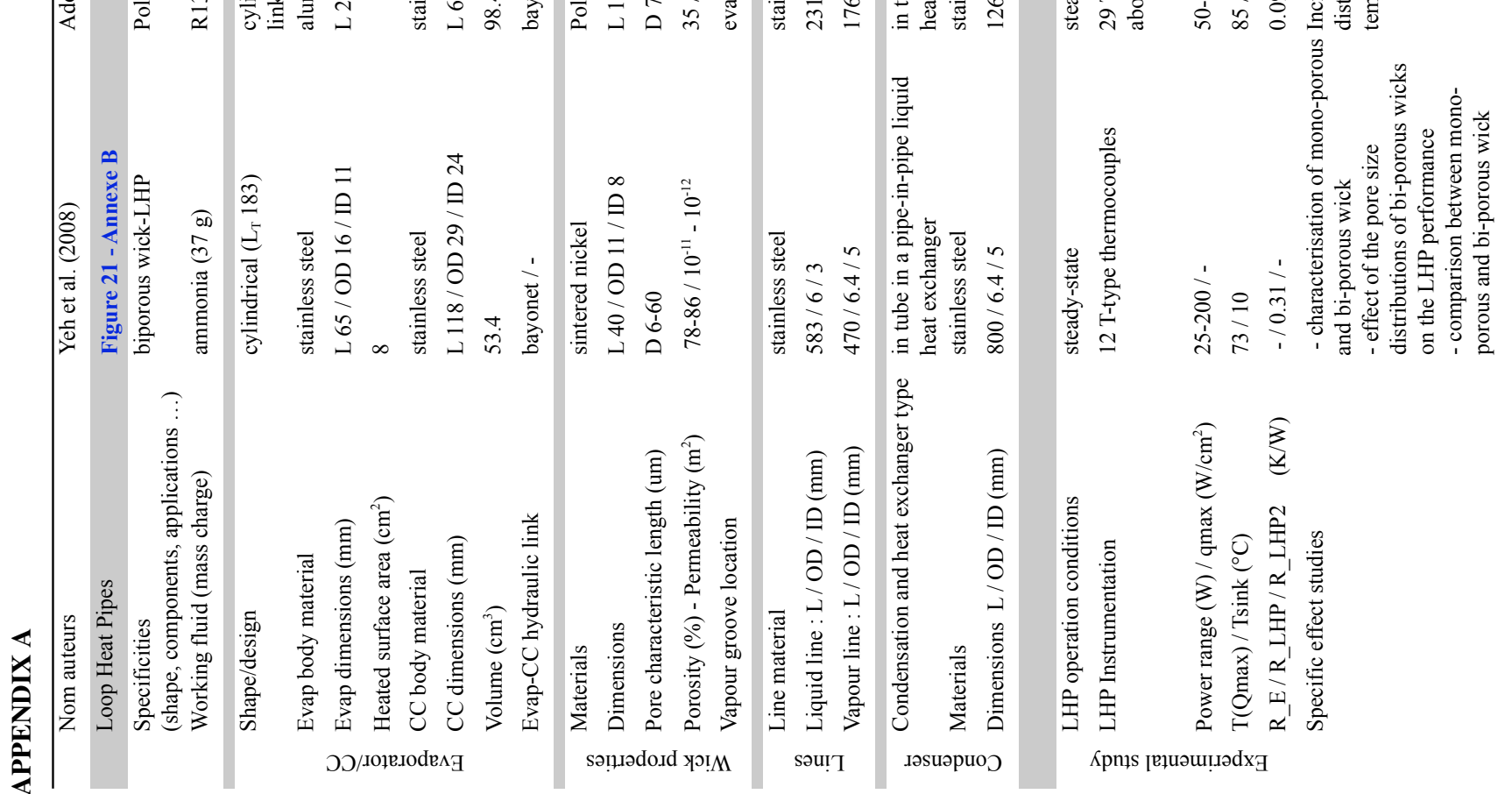


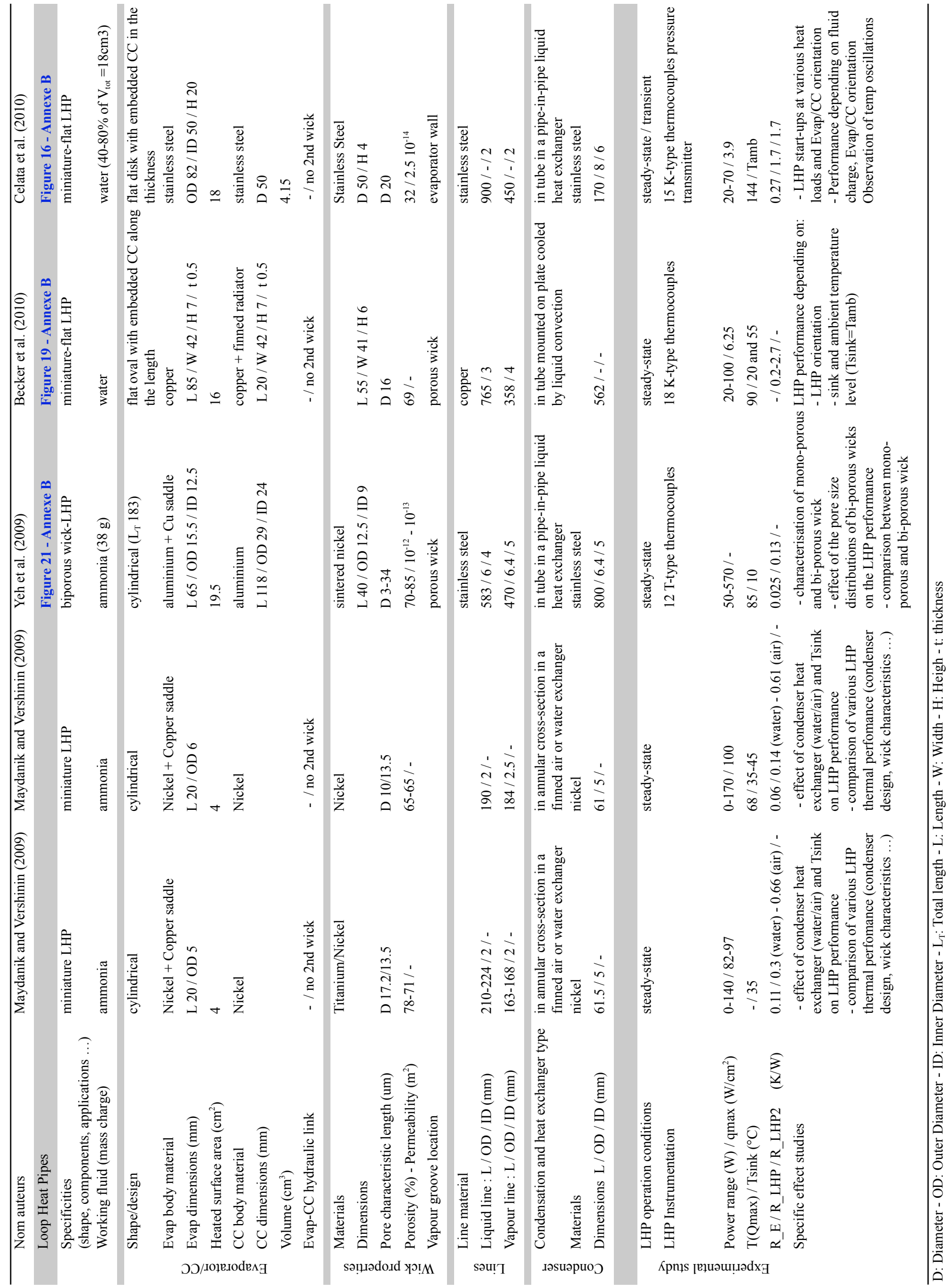




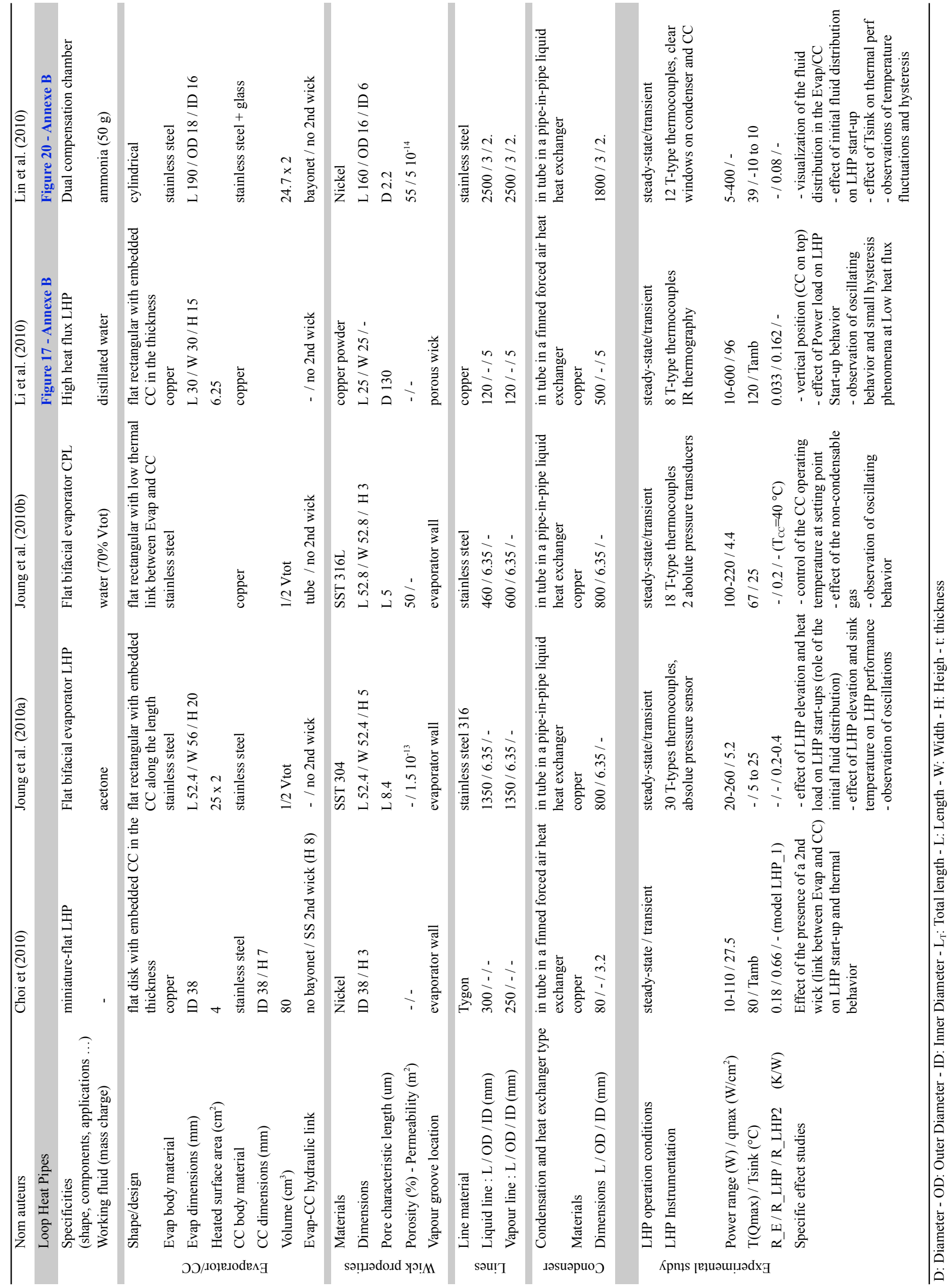




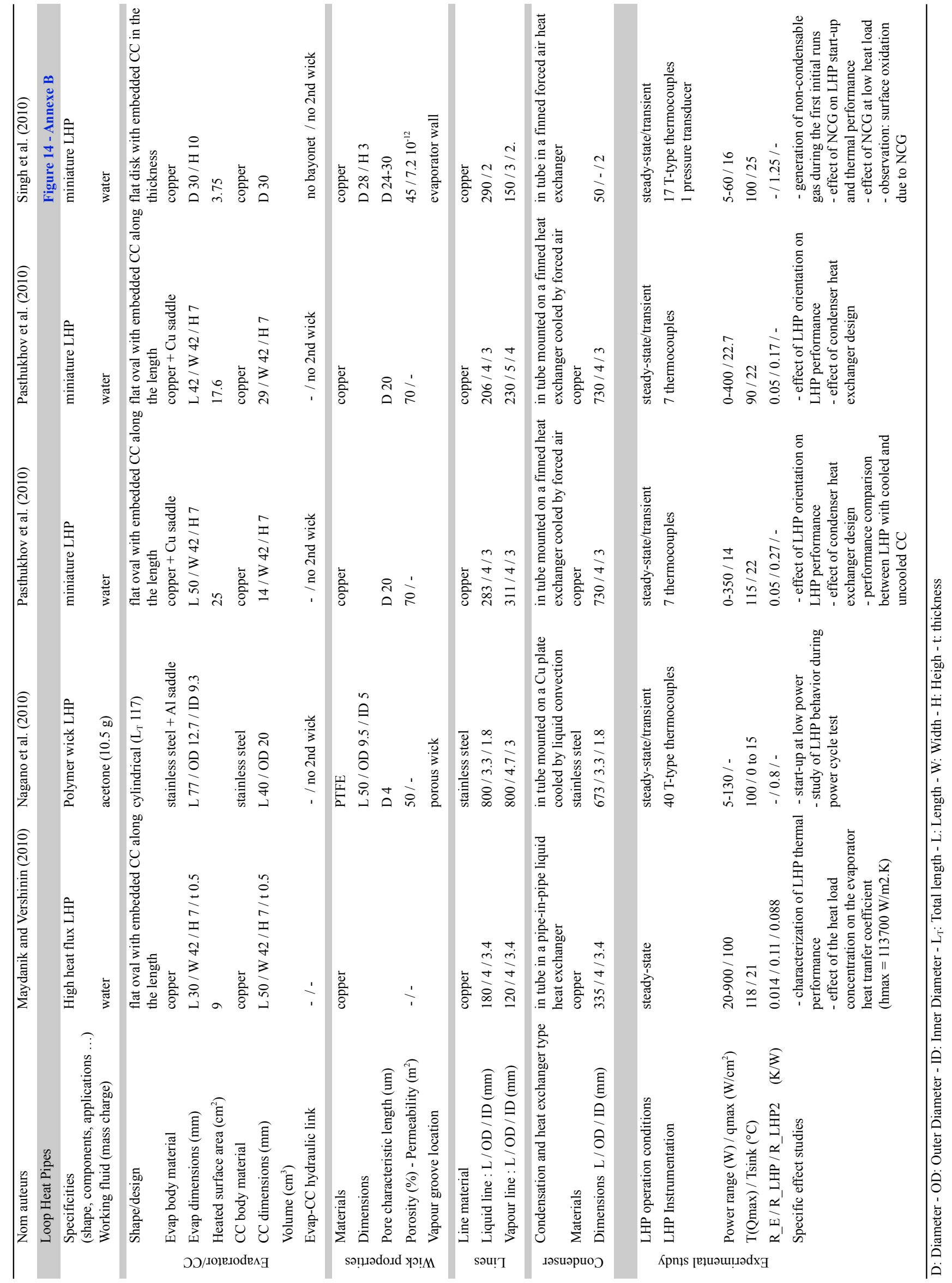



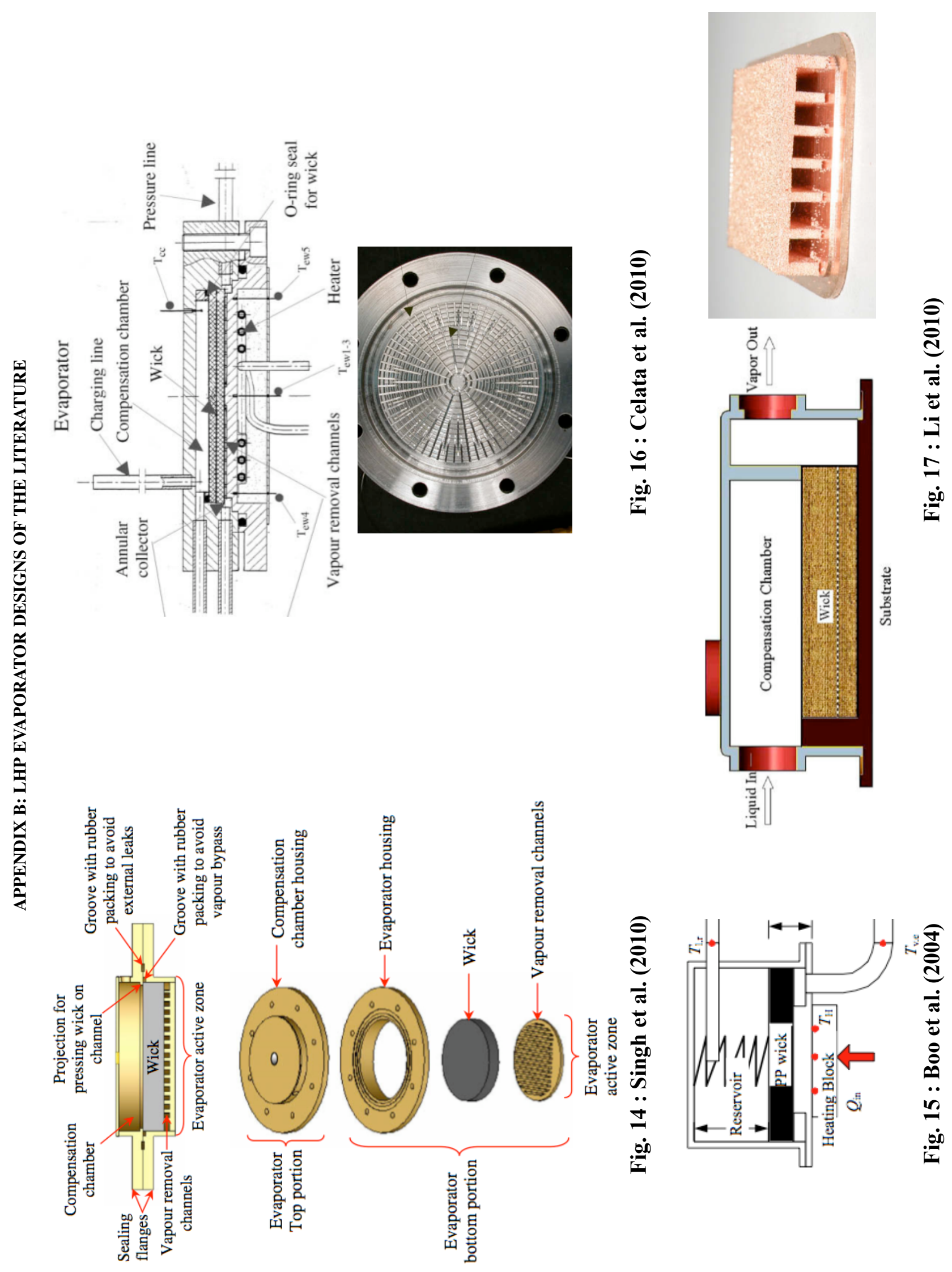

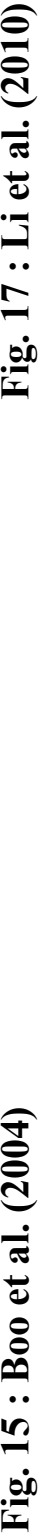



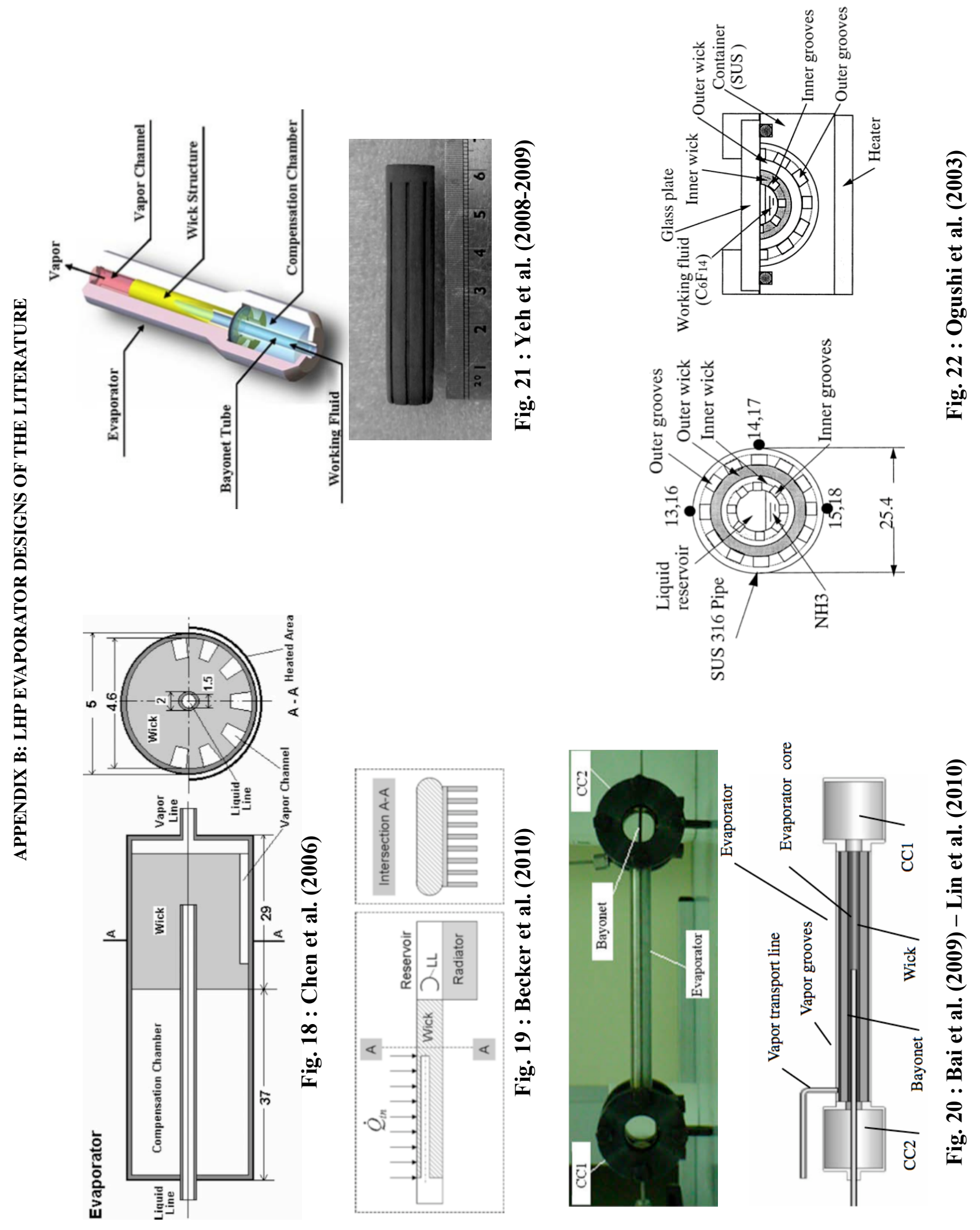